OPEN ACCESS

Edited by:

Selwin KWu,

National University of Singapore,

Singapore

Reviewed by:

Stefaan Verbruggen,

The University of Sheffield,

United Kingdom

Danielle Wu,

University of Texas Health Science

Center at Houston, United States

${ }^{*}$ Correspondence:

Alan E. Rowan

alan.rowan@uq.edu.au

Jung Un Ally Choi

jung.choi@uq.edu.au

Specialty section:

This article was submitted to

Cell Adhesion and Migration,

a section of the journal

Frontiers in Cell and Developmental

Biology

Received: 03 September 2021

Accepted: 13 December 2021

Published: 21 February 2022

Citation:

Choi JUA, Kijas AW, Lauko J and Rowan AE (2022) The Mechanosensory Role of Osteocytes and Implications for Bone Health and

Disease States.

Front. Cell Dev. Biol. 9:770143. doi: $10.3389 /$ fcell.2021.770143

\section{The Mechanosensory Role of Osteocytes and Implications for Bone Health and Disease States}

\author{
Jung Un Ally Choi *, Amanda W. Kijas, Jan Lauko and Alan E. Rowan* \\ Australian Institute for Bioengineering and Nanotechnology, The University of Queensland, Brisbane, QLD, Australia
}

Bone homeostasis is a dynamic equilibrium between bone-forming osteoblasts and boneresorbing osteoclasts. This process is primarily controlled by the most abundant and mechanosensitive bone cells, osteocytes, that reside individually, within chambers of porous hydroxyapatite bone matrix. Recent studies have unveiled additional functional roles for osteocytes in directly contributing to local matrix regulation as well as systemic roles through endocrine functions by communicating with distant organs such as the kidney. Osteocyte function is governed largely by both biochemical signaling and the mechanical stimuli exerted on bone. Mechanical stimulation is required to maintain bone health whilst aging and reduced level of loading are known to result in bone loss. To date, both in vivo and in vitro approaches have been established to answer important questions such as the effect of mechanical stimuli, the mechanosensors involved, and the mechanosensitive signaling pathways in osteocytes. However, our understanding of osteocyte mechanotransduction has been limited due to the technical challenges of working with these cells since they are individually embedded within the hard hydroxyapatite bone matrix. This review highlights the current knowledge of the osteocyte functional role in maintaining bone health and the key regulatory pathways of these mechanosensitive cells. Finally, we elaborate on the current therapeutic opportunities offered by existing treatments and the potential for targeting osteocytedirected signaling.

Keywords: bone homeostasis, osteocytes, integrins, mechanotransduction, signaling pathway, aging, osteoporosis, bone therapeutics

\section{INTRODUCTION}

The most long-lived bone cells, osteocytes are known as the master regulator of bone formation and resorption (Bonewald 2011). The mechanosensory role of osteocytes underlies well-balanced bone homeostasis, which is primarily influenced by matrix strain and fluid shear stress (Weinbaum et al., 1994; Han et al., 2004; Robling and Turner 2009; Wittkowske et al., 2016). Through mechanotransduction processes, osteocytes are able to transduce extracellular signals to elicit cellular responses by initiating different signaling pathways accordingly to bring functional responses. The dysregulation of osteocyte behavior can lead to reduced bone mass and bone fragility observed in osteoporotic patients. For this reason, osteocyte-induced mechanotransduction has been studied extensively, however, the exact mechanisms and signaling pathways are not fully understood. Here we highlight the crucial role of osteocytes in bone homeostasis, including regulation of the overall bone remodeling process, perilacunar/canalicular remodeling, and 
systemic regulatory roles on other tissues such as the kidney, parathyroid, and heart (Dallas et al., 2013; Creecy et al., 2021). Furthermore, we summarize the osteocyte mechanosensors and the current state of mechanoresponsive signaling pathways identified in osteocytes with therapeutic implications. To achieve this, we present both in vivo and in vitro approaches that have been employed to understand the complex regulatory processes that underly osteocytes' quintessential mechanosensory role in bone.

\section{BONE HOMEOSTASIS}

Bone is a weight-bearing tissue, which supports locomotion, protects soft tissue, and is also known as a reservoir for calcium and phosphate (Bellido 2014; Florencio-Silva et al., 2015). Bones are composed of both organic matrix, comprising of largely type I collagen (90\%), with the remaining protein component including osteocalcin, osteonectin, osteopontin, fibronectin, and thrombospondin-2 (Sroga and Vashishth 2012), as well as inorganic matrix minerals, mainly comprised of hydroxyapatite $\left(\mathrm{Ca}_{5}\left(\mathrm{PO}_{4}\right)_{3} \mathrm{OH}\right)$ but also including small amounts of potassium, magnesium, sodium, strontium, and calcium salts (Lin et al., 2020). The formation of the bone matrix is initiated by the collagen assembly followed by hydroxyapatite deposition and tuned by minerals and amino acids of non-collagenous proteins (Young 2003; Tavafoghi and Cerruti 2016). The balance of mineral content is important and directly relates to mechanical strength (Faibish et al., 2006). For example, bones become brittle when mineral content is too high and less load-bearing if the mineral content is too low. This mineralized tissue undergoes remodeling to maintain its integrity and is tightly regulated by a precise balance of bone formation and resorption under the control of local and systemic factors, such as cytokines, hormones, and mechanical stimulation (Florencio-Silva et al., 2015). This complex process is a cycle of localized bone resorption to remove old or damaged bone followed by a longer phase of bone formation, both in an equilibrium to maintain healthy bone. The imbalance of this regulation often leads to bone diseases such as osteoporosis and is caused by a variety of factors such as aging, menopause, drugs, and changes in physical activity (Feng and McDonald 2011). Imbalance can also stem from genetic mutations, leading to bone overgrowth disorders due to defective signaling pathways that change the equilibrium resulting in van Buchem disease and sclerosteosis (Balemans et al., 1999; Sebastian and Loots 2018).

Bone is a rigid and load-bearing tissue designed to sustain high mechanical loads during exercise (Benedetti et al., 2018). There are two types of bone tissue, the cortical and trabecular bone, which have the same cells and matrix but differ in structuralfunctional roles (Clarke 2008). Cortical bones are more calcified and hard, and carry out the role of providing mechanical stability and form a protective layer for the internal cavity (Boskey and Coleman 2010). In comparison, the trabecular bones only contain $1 / 3$ of calcified bone compared to the cortical ones and are mainly involved in metabolic as well as biomechanical functions (Clarke
2008). The composition of the bone matrix is important for fracture resistance, which largely depends on the geometric (size and shape) and material properties (mineral content and composition) (Osterhoff et al., 2016). Bones constantly experience mechanical forces created by various stimuli including fluid flow shear stress, hydrostatic pressure, and direct cellular deformation induced by gravitational forces as a weight-bearing tissue and loading-induced stimuli such as compressive force. The calcified bone matrix may induce micro-deformation with a maximum of $3 \%$ strain changes (Hart et al., 2017). The matrix deformation during locomotion is between 0.04 and $0.3 \%$ but hardly exceeds $0.1 \%$. Surprisingly in vitro studies need to apply more than 10 times this mechanical stimulation to observe osteocyte responses, otherwise, the strain amplification at the cellular level is too small to initiate mechanotransduction pathways (Rubin and Lanyon 1984; Fritton et al., 2000). These in vitro forces applied back at the tissue level would cause a fracture (Burr et al., 1996; You et al., 2000; Wang et al., 2015). This difference has to be taken into consideration to more accurately capture the differences between in vivo and in vitro systems and facilitate the accurate interpretation of a translational approach. The externally applied force is transduced by highly mechanosensitive osteocytes that coordinate the effector cells, bone-forming osteoblasts, and bone-resorbing osteoclasts demonstrating the skeletal adaptation response of mechanical cues into biochemical signals (Bonewald 2011; Schaffler and Kennedy 2012). The above highlights the need to understand the mechanisms underlying osteocyte's important regulatory role in bone homeostasis.

\section{OSTEOCYTES, THE MASTER REGULATOR}

Osteocytes are the most abundant ( 95\%) bone cells, which reside in the hard bone matrix (Hellmich and Ulm 2002; Bonewald 2011). Osteocytes are a terminally differentiated post-mitotic cell type from the osteogenic lineage, derived from mesenchymal stem cell progenitors (Pittenger et al., 1999; Day et al., 2005; Gaur et al., 2005; Sudo et al., 2007). Mesenchymal stem cell differentiation leads to osteoblasts, and a subpopulation is known to terminally differentiate into osteocytes that are individually embedded within small chambers called lacunae (Palumbo et al., 1990; Candeliere et al., 2001). After the differentiation process, the most striking morphological change of mature osteocytes is the development of unique dendritic cell processes. These dendritic cell processes create an extensive cellular network in the hard bone matrix, which enables osteocytes to communicate with neighboring osteocytes, and the osteoblasts and osteoclasts on the bone surface by creating a neuron-like network (Palumbo et al., 1990). This highly complex communication network, is created through a space called canaliculi, which are narrow channels in the hydroxyapatite matrix. Osteocytes are separated from the mineralized bone matrix, by a pericellular space filled with proteoglycan-rich matrix (glycocalyx) and interstitial fluid (Termine et al., 1981; Sauren et al., 1992; Aarden et al., 


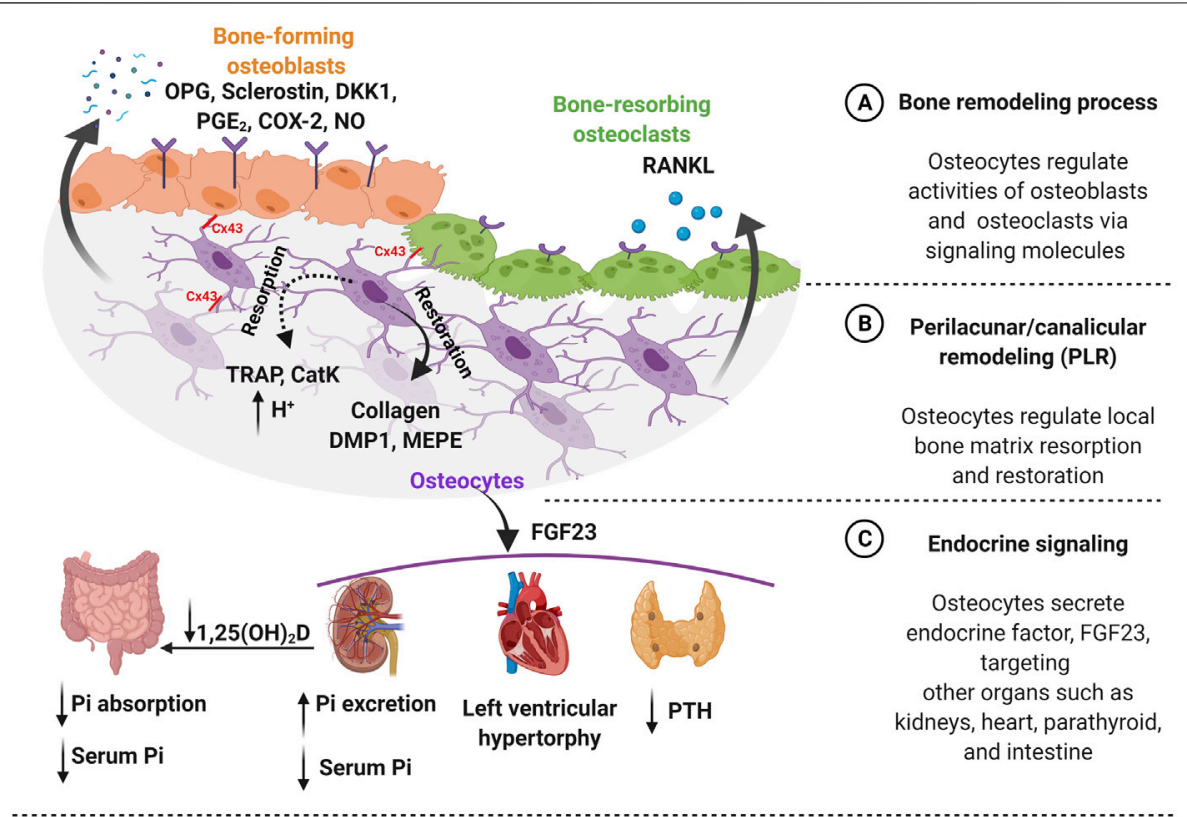

FIGURE 1 | Osteocytes function in both bone homeostasis and endocrine signaling. (A) Bone homeostasis is guided by osteocytes, which require a precise balance of bone formation and bone resorption. Osteocytes regulate this dynamic equilibrium by releasing signaling molecules such as osteoprotegerin (OPG), sclerostin, dickkopf-related protein 1 (DKK1), prostaglandin E2 ( $\mathrm{PGE}_{2}$ ), cyclooxygenase-2 (COX-2), and nitric oxide (NO) for bone-forming osteoblasts. Furthermore, osteocytes secrete receptor activator of nuclear factor- $\mathrm{kB}$ ligand (RANKL) for bone-resorbing osteoclasts on the bone surface. Additionally, osteocytes mediate communication with osteoblast and osteoclast via connexin 43 (Cx43) gap junctions. (B) Osteocytes regulate the local bone matrix through a process called perilacunar/ canalicular remodeling (PLR). Matrix resorption (dotted line) is initiated creating an acidic environment by osteocyte-derived enzymes, such as tartrate-resistant acid phosphatase (TRAP) and cathepsin K (CatK) followed by matrix restoration (solid line), by producing collagen and bone matrix proteins such as dentin matrix protein 1 (DMP1) and matrix extracellular phosphoglycoprotein (MEPE). (C) Osteocytes secrete an endocrine factor - fibroblast growth factor (FGF23) to target other organs such as kidneys, heart, and parathyroid. The FGF23 hormone triggers parathyroid to reduce the level of parathyroid hormone (PTH). Moreover, FGF23 increases the risk of heart failure such as left ventricular hypertrophy. Importantly, FGF23 regulates serum phosphate (Pi) level by targeting kidneys by increasing phosphate excretion and also inhibiting the conversion of active vitamin $D$ to 1,25-dihydroxy vitamin $D\left[1,25(\mathrm{OH})_{2} \mathrm{D}\right]$ in the intestine to decrease phosphate resorption leading to lower serum phosphate level. Figure created using BioRender.

1996). Based on the measurements and mathematical models for branching, these dendritic processes were estimated to form approximately 23 trillion connections and span a total length of over $175000 \mathrm{~km}$ within the human body (Buenzli and Sims 2015). In vivo, each cell has been shown to have a varying number of dendritic cell processes ranging from 18 to 106, which reduces with aging (Beno et al., 2006; Qin et al., 2020). Initial development of dendritic cell processes from the cell body leads to the formation of subsequent subbranches, which create sufficient surface area for efficient communication with other cells and also serving as a mechanosensory structures. The unique environment for osteocytes is called the lacunocanalicular network (LCN) and is a complicated network within bone tissue with a total surface area of approximately $215 \mathrm{~m}^{2}$ (Sims 2016; Martin 2019) and is also thought to provide a route for the provision of nutrients, oxygen, and biochemical signals.

Since osteocytes reside in this unique LCN architecture of mineralized matrix, it has been a challenge to study osteocytes. In spite of this challenge, a variety of mechanical stimulations such as fluid flow shear stress, and substrate deformation are known to influence osteocytes functions (You et al., 2000; McGarry et a., 2005; Wittkowske et al., 2016; Qin et al., 2020). It is important to understand that loading-induced matrix deformation not only changes fluid flow velocity, but also the matrix strain, which is closely associated with the $\mathrm{LCN}$ architecture. A recent study demonstrated that the LCN architecture is a key determinant for bone adaption in response to mechanical stimulation (van Tol et al., 2020). The fluid flow-induced velocity was strongly dependent on the LCN architecture in a highly dense and connected network (Denisov-Nikol'skiǐ Iu and Doktorov, 1987; Johnson 1984). Another study observed that the fluid flow velocity was not directly correlated to the loading-induced strain deformation, but more associated with the LCN structure based on in vivo mice micro-computed tomography (microCT) evaluations (van Tol et al., 2020). The changes in the strain distributions of the LCN upon applying various static and cyclic loads highlighted the diversity of mechanosensors on these cells and complexity of the underlying mechanotransduction pathways (Wang et al., 2015). The dendritic morphology of osteocytes itself is also proposed to be synergistic with the highly-dense LCN network, resulting in an actin-rich cytoskeleton, which enables cell-cell communications between osteocytes allowing a cascade of intracellular events capable of generating a functional response (Burra et al., 2010; Hemmatian et al., 2017). 


\section{OSTEOCYTE FUNCTIONS IN BOTH BONE AND EXTRASKELETAL ROLES}

As osteocytes are embedded individually within the bone and separated from the effector bone cell types, they utilize secreted signaling molecules to communicate their "instructions" in addition to their broader systemic effects (Dallas et al., 2013; Prideaux et al., 2016). Osteocytes are involved in the secretion of signaling molecules, to regulate osteoblast and osteoclast activities, as well as establishing direct physical connections via gap junctions (Figure 1A). The quintessential molecule in bone regulation is the osteocyte-specific sclerostin, which is exclusively expressed by mature osteocytes. Sclerostin is an anti-bone formation (antagonist) regulator that directly inhibits the proliferation and differentiation of osteoblasts (Duan and Bonewald 2016). The osteoblast-induced bone formation is initiated by secreted Wnt ligand glycoproteins, which bind to low-density lipoprotein receptors (LRP) 4/5/6 for phosphorylation, leading to suppression of glycogen synthase kinase 3 (GSK3) (Karner and Long 2017). This stabilizes $\beta$-catenin, which then translocates into the nucleus, and acts as a transcriptional co-activator. Sclerostin, the protein product of the SOST gene expressed by mature osteocytes, binds to the LRP 4/5/6 to inhibit Wnt-binding for the Wnt/ $\beta$-catenin signaling pathway in osteoblasts. Sclerostin expression is also known to be decreased by mechanical loading and increased in response to unloading conditions such as microgravity and reduced physical levels in bed-ridden patients (Pajevic et al., 2013; Bradbury et al., 2020).

The osteocyte-secreted dickkopf-related protein 1 (DKK1) binds to LRP4/5/6 on osteoblasts and acts as a Wnt competitive inhibitor ( $\mathrm{Li}$ et al., 2006). Osteocytes also secrete osteoprotegerin (OPG), a soluble decoy receptor for receptor activator of nuclear factor- $\mathrm{KB}$ ligand (RANKL), which is a cytokine that binds to osteoclasts, promoting bone resorption (Kearns, Khosla, and Kostenuik 2008). The ratio between OPG and RANKL is commonly used as an indicator of bone mass and decreased RANKL/OPG ratio was reported in response to mechanical stimulation, leading to reduced osteoclast activity (Goldring 2015). Interestingly, proinflammatory cytokines were also observed to be down-regulated by mechanical loading, except interleukin 6 (IL-6) (Pathak et al., 2015; Pathak et al., 2020). Mechanical stimulation modulates the release of other factors such as nitric oxide (NO), prostaglandin E2 ( $\left.\mathrm{PGE}_{2}\right)$, cyclooxygenase-2 (COX-2), and adenosine triphosphate (ATP) in osteocytes (Li et al., 2021). Especially, loading-induced calcium ions $\left(\mathrm{Ca}^{2+}\right)$ oscillation releases signaling molecules such as NO, $\mathrm{PGE}_{2}$, insulin-like growth factor-1 (IGF-1), and $\beta$-catenin, which are important for osteocyte viability and anabolic effect on bone (Morrell et al., 2018).

Osteocytes, embedded in the hard bone matrix are also known to regulate their local microenvironment through a process called perilacunar/canalicular remodeling (PLR) (Figure 1B) (Qing and Bonewald 2009; Lin et al., 2020). Earlier studies observed the enlarged lacunae during lactation to release calcium from a mineralized matrix for high calcium demand situations and also in pathological conditions such as
Paget's disease, a bone loss disorder, suggesting the removal of perilacunar matrix by osteocytic osteolysis (Zambonin Zallone et al., 1982; Teti and Zallone 2009; Tsourdi et al., 2018). However, this microenvironment remodeling is also known as a homeostatic mechanism to maintain the perilacunar/canalicular network under healthy conditions such as lactation (Dole et al., 2017). Interestingly, osteocytes are able to remove both minerals and collagen from their surrounding perilacunar matrix by upregulating the $\mathrm{H}^{+}$proton pump, creating an acidic microenvironment (Qing et al., 2012; Creecy et al., 2021). The acidic environment can be induced by the parathyroid hormone (PTH) upregulation during lactation (Jähn et al., 2017). Osteocyte-derived matrix removal was observed in lactating mice showing the enlarged lacunar area with upregulation of tartrate-resistant acid phosphatase (TRAP) and cathepsin $\mathrm{K}$ (CatK, encoded by the Ctsk gene), which were previously thought to be osteoclast-specific (Nakano et al., 2004; Qing et al., 2012; Lotinun et al., 2019). TRAP is an enzyme that is responsible for the dephosphorylation of bone matrix phosphoproteins and $\mathrm{CatK}$ is a lysosomal cysteine protease that contains the catalytic mechanism necessary for bone matrix degradation leading to bone resorption (Dai et al., 2020). By increasing osteoclast-like markers, they create an acidic environment via carbonic anhydrase 2 (Car2) and proton-pumping vacuolar ATPases.

Recent research hinted that transforming growth factor beta (TGF- $\beta$ ) is possibly associated with the PLR process (Schurman et al., 2021). In vitro studies have demonstrated TGF- $\beta$ treatment upregulated Ctsk and matrix metalloproteinase 14 gene expressions in both osteocytic cell lines, MLO-Y4 and Ocy454 (Dole et al., 2017; Kegelman et al., 2020). Furthermore, intracellular $\mathrm{pH}(\mathrm{pHi})$ has been shown to decrease after TGF$\beta$ treatment, resulting in cell acidification, inducing PLR resorption that was dependent on the TGF- $\beta$ receptors on osteocytes (Dole et al., 2017). TGF- $\beta$ intake by osteocytes was blocked by using type I TGF- $\beta$ receptor (T $\beta$ RI) inhibitor (SB431542), and lead to increased $\mathrm{pH}$ levels, equivalent to untreated groups. In vivo studies using osteocyte-specific TGF- $\beta$ receptor knockout mice showed decreased expression of Ctsk leading to decreased bone resorption contributing to increased bone mass in these animals. (Dole et al., 2017; Schurman et al., 2021). Furthermore, TGF- $\beta$ treatment induced changes in gene expression levels of sclerostin in osteocytes. PLR was also induced in osteocytes after recombinant human sclerostin (rhSCL) treatment, which lowers the $\mathrm{pHi}$ showing upregulation of catalytic genes (e.g., Ctsk, Car2, TRAP) (Kogawa et al., 2013). This suggests that osteocyte-produced sclerostin promotes catalytic activity to release the minerals. Moreover, rhSCL treatment in human trabecular bone samples showed an increased lacunar area around osteocytes (Kogawa et al., 2018). The activity of sclerostin was also confirmed by Lrp $4 / 5 / 6$ receptors, known for sclerostin binding inhibited osteocyte-mediated catalytic activity for the removal of bone matrix in PLR. However, further investigation is required to understand the mechanisms of PLR, which is different from osteoclast-mediated bone resorption. 
It is well known that the increased lacunar area returns to normal after the weaning process suggesting osteocytes play a role in local matrix restoration. It was proposed, that the local PLR remodeling process was independent of mechanical stimulation and was presumed to be hormonally regulated (Qing et al., 2012; Bach-Gansmo et al., 2016). However, a recent study of mice under microgravity conditions, which removes mechanical loading on bones, observed enlarged lacunae size and deformed bone microstructure in these animals (Gerbaix et al., 2017). For osteocytes to perform PLR, both collagen production and mineralization are essential for the matrix restoration process. Previous studies support the osteocyte-driven collagen production using novel GFP-collagen transgenic mice (Baylink and Wergedal 1971; Zambonin Zallone et al., 1982; KamelElSayed et al., 2015). They observed bright collagen production around some osteocytes suggesting heterogeneity in the osteocyte population has a capability of collagen production for PLR restoration. The fact that the collagenous matrix aligned with the axis of the lacunae, suggests collagen orientation and alignment are also coordinated by osteocytes. During this process, the levels of bone matrix proteins such as dentin matrix protein 1 (DMP1) and matrix extracellular phosphoglycoprotein (MEPE) in osteocytes were highly upregulated to support the mineralization process (GluhakHeinrich et al., 2007; Harris et al., 2007; Teti and Zallone 2009; Qing et al., 2012).

PLR contributes to bone quality by altering the mineral to matrix ratio ( $\mathrm{M} / \mathrm{M}$ ratio), which is often used to predict the biomechanical properties of bone (Takata et al., 2011). The M/M ratio often increases with elevated bone mineral density contributing to better bone quality and is significantly increased with exercise (Kohn et al., 2009; Gardinier et al., 2016). In vivo studies of mice undertaking treadmill running, showed an increased $\mathrm{M} / \mathrm{M}$ ratio around the matrix close to osteocytes compared to the bone matrix further away, suggesting localized osteocyte-induced PLR (Gardinier et al., 2016). This finding suggests that PLR regulation takes place predominantly in the mineralized bone matrix such as cortical bone. A better understanding of the mechanism of PLR regulation will aid in developing potential therapeutic applications that could improve cortical bone integrity, which is known to have a lower recovery rate after fracture compared to trabecular fractures (Chen and Sambrook 2011; Rivadeneira and Mäkitie 2016).

Osteocytes are known to secrete signaling factors into the circulatory system to modulate behavior of distant target organs such as parathyroid, kidney, and heart (Martin 2019; Pathak et al., 2020; Florencio-Silva et al., 2015). Particularly, osteocyte-secreted factor, fibroblast growth factor 23 (FGF23) that plays a role in endocrine signaling (Figure 1C). FGF23 contributes to kidney functions, maintaining serum phosphate levels by modulating the expression level of sodium/phosphate co-transporters in the kidney (Bonewald and Wacker 2013; Dallas et al., 2013; Dussold et al., 2019). Through this mechanism, FGF23 suppresses the vitamin D hormone (1,25dihydroxyvitamin D) production in the kidneys by inhibiting the conversion of 25-hydroxyvitamin $\mathrm{D}$ to the active form, 1,25-dihydroxyvitamin $\mathrm{D}$ by 1- $\alpha$-hydroxylase (Martin, David, and Quarles 2012; Dallas et al., 2013). The high FGF23 levels inhibit the vitamin D conversion process leading to decreased phosphate absorption in the intestine. This signaling process is tightly regulated by a feedback system between the active form of vitamin D and the level of FGF23 in circulation, where osteocytes play a key role. The elevated levels of circulating FGF23 are known as a risk factor for heart disease such as left ventricular hypertrophy, but further investigation is required to understand the underlying mechanism of FGF23 in this tissue (Mirza et al., 2009; Desjardins et al., 2012). The high prevalence of heart failure is often seen in chronic kidney disease (CKD) patients, which is also associated with elevated levels of FGF23 (Scialla et al., 2014). Furthermore, the parathyroid gland is another target for FGF23, which decreases PTH secretion. Where increased FGF23 levels modulate the downregulation of $\mathrm{PTH}$ mRNA expression and secretion in vitro (Krajisnik et al., 2007). The important and wellcharacterized role of PTH is in maintaining systemic calcium levels, where the parathyroid gland-secreted PTH is known to respond to low serum calcium (Bellido et al., 2013). If there is a high calcium demand in the intestine, the PTH levels increase causing mineral release from bones, which is often seen in pathological conditions such as chronic kidney disease. Osteocytes closely coordinate this process by increasing mineral degradation through PLR. Osteocytesecreted CatK also contributes to the regulation of PTH levels by increasing parathyroid hormone-related peptide (PTHrP) during lactation (Lotinun et al., 2019).

\section{MECHANOSENSORS IN OSTEOCYTES}

Osteocytes are known to be one of the most mechanosensitive cells (Jacobs et al., 2010). These cells can be stimulated by various mechanical forces in bone created by gravitational forces and daily activities leading to changes of interstitial fluid flow and matrix deformation at the cellular level in bone. The osteocyte cellular response to mechanical stimulation is crucial in terms of viability, and also for a regulatory role in balanced bone homeostasis (Qin et al., 2020; Wittkowske et al., 2016). The earlier studies primarily focused on fluid flow-induced osteocyte mechanotransduction compared to direct interaction with extracellular matrix (ECM) deformation (Cheng et al., 2001a; Cherian et al., 2005; Kulkarni et al., 2010; Li et al., 2012; Spatz et al., 2015; Qin et al., 2020). The fluid flow rate used in previous in vitro studies was between 0.5 and 2 dynes $/ \mathrm{cm}^{2}$ ( 0.5 and $2 \mathrm{~Pa}$ ) with some studies using up to 16 dynes $/ \mathrm{cm}^{2}$ (Table 1). These studies were demonstrated using both osteocyte cell lines (Cheng et al., 2001b; Cherian et al., 2005; Kulkarni et al., 2010; Litzenberger et al., 2010; Li et al., 2012; Xu et al., 2012; Spatz et al., 2015; Sato et al., 2020) and primary osteocytes (Ajubi et al., 1996; Klein-Nulend et al., 1997; Sterck et al., 1998; Ajubi et al., 1999; Joldersma et al., 2000). However, the exact physiological flow rate remains 
TABLE 1 | Summary table for in vitro studies on osteocytes in response to mechanical stimulations. Abbreviations: Sclerostin (Sost), cyclooxygenase-1 (COX-1), osteoprotegerin (OPG), receptor activator of nuclear factor- $\mathrm{kB}$ ligand (RANKL), podoplanin (E11), prostaglandin $\mathrm{E}_{2}(\mathrm{PGE} 2)$, cyclooxygenase-2 (COX-2), connexin 43 (Cx43), matrix extracellular phosphoglycoprotein (Mepe), phosphate regulating endopeptidase homologue, X-linked (Phex), dentin matrix protein 1 (Dmp1).

\begin{tabular}{|c|c|c|c|}
\hline Cell type & Mechanical stimulation & Gene/Protein expression & Outcome \\
\hline \multicolumn{4}{|l|}{ Osteocyte cell lines } \\
\hline MLO-Y4 & Oscillatory fluid flow, $1 \mathrm{~Pa} / 2 \mathrm{~h}$ & COX-2, RANKL/OPG & $\begin{array}{l}\text { Response of integrin } \beta 1 \text { under oscillatory fluid flow. The absence of } \beta 1 \\
\text { showed a reduction in COX-2 and PGE } 2 \text { (Litzenberger et al., 2010) }\end{array}$ \\
\hline MLO-Y4 & Oscillatory fluid flow, $1 \mathrm{~Pa} / 2 \mathrm{~h}$ & COX-2, Runx-2, integrin aV $\beta 3, \mathrm{E} 11$ & $\begin{array}{l}\text { Increased expression of integrin-associated molecules including vinculin, } \\
\text { osteopontin, and CD44. Also, more cell spread and fiber stress are } \\
\text { formed by fluid flow (Xu et al., 2012; Zhang et al., 2015) }\end{array}$ \\
\hline MLO-Y4 & $\begin{array}{l}\text { Oscillatory fluid flow, } 0.5-5 \mathrm{~Pa} / \\
1-4 \mathrm{~Pa}\end{array}$ & COX-2, RANKL/OPG & $\begin{array}{l}\text { Cells were exposed to different shear stress amplitude }(0.5-5 \mathrm{~Pa}) \text {, } \\
\text { oscillating frequency }(0.5-2 \mathrm{~Hz}) \text {, and duration }(1-4 \mathrm{~h}) . \text { COX-2 } \\
\text { Upregulated gene expression levels for COX-2 response to higher shear } \\
\text { stress amplitudes, faster oscillating frequencies, and longer flow } \\
\text { durations, which direct towards bone formation ( } \mathrm{Li} \text { et al., 2012) }\end{array}$ \\
\hline MLO-Y4 & $\begin{array}{l}\text { Fluid shear stress, } 16 \mathrm{~Pa} \\
0.5-2 \mathrm{~h}\end{array}$ & $\mathrm{OPG}, \mathrm{C} \times 43, \mathrm{PGE}_{2}$ & $\begin{array}{l}\text { Fluid shear stress induces the opening of } \mathrm{C} \times 43 \text { and redistributes } \mathrm{C} \times 43 \\
\text { protein, which promotes } \mathrm{PGE}_{2} \text { release (Chen and Sambrook, 2001; } \\
\text { Cherian et al., 2005) }\end{array}$ \\
\hline MLO-Y4 & Pulsating fluid flow, $0.7 \mathrm{~Pa} / 1 \mathrm{~h}$ & Mepe, RANKL/OPG & $\begin{array}{l}\text { Pulsatile fluid flow induced Mepe, but not Phex. RANKL/OPG gene } \\
\text { expression decreased (Kulkarni et al., 2010) }\end{array}$ \\
\hline Ocy454 & $\begin{array}{l}\text { 3D fluid shear stress, } \\
0.5-2.0 \mathrm{~Pa} / 2 \text { h or } 3 \text { days }\end{array}$ & $\begin{array}{l}\text { Sost, Dmp1, RANKL, OPG, Phex, } \\
\text { Mepe, Osteocalcin }\end{array}$ & $\begin{array}{l}\text { Long-term fluid shear stress (3 days) in 2D LS increases Sost, Dmp1, } \\
\text { RANKL, OPG, Phex, Mepe (Spatz et al., 2015; Wein et al., 2015) }\end{array}$ \\
\hline Ocy454 & $\begin{array}{l}\text { Laminar fluid flow, } 0.8 \mathrm{~Pa} \\
45 \mathrm{~min}\end{array}$ & Sost & $\begin{array}{l}\text { Laminar fluid flow downregulated Sost gene expression and } \\
\text { demonstrated HDAC5 is required for loading-induced Sost suppression } \\
\text { (Sato et al., 2020) }\end{array}$ \\
\hline \multicolumn{4}{|l|}{ Primary osteocytes } \\
\hline Chicken osteocytes & $\begin{array}{l}\text { Pulsating fluid flow, } 0.5 \mathrm{~Pa} / 1 \mathrm{~h} \text {, } \\
0.7 \mathrm{~Pa} / 10 \mathrm{~min}\end{array}$ & $\mathrm{PGE}_{2}$ & $\begin{array}{l}\text { Osteocytes rapidly respond to fluid flow to increase PEG } 2 \text { (Ajubi et al., } \\
\text { 1996) } \\
\text { Intracellular } \mathrm{Ca}^{2+} \text { level was increased through mechanosensitive ion } \\
\text { channels (Ajubi et al., 1999) }\end{array}$ \\
\hline Mouse calvariae & Pulsating fluid flow, $0.7 \mathrm{~Pa} / 1 \mathrm{~h}$ & $\begin{array}{l}\text { PGHS-2 (Prostaglandin } \mathrm{G} / \mathrm{H} \\
\text { synthase), } \text { PGE }_{2}\end{array}$ & $\begin{array}{l}\text { After pulsating fluid flow, osteocyte s upregulated PGHS-2 gene } \\
\text { expression, leading to more conversion of arachidonic acid into PGE } 2 \\
\text { (Klein-Nulend et al., 1997) }\end{array}$ \\
\hline $\begin{array}{l}\text { Human calvarial } \\
\text { cells/biopsies }\end{array}$ & Pulsating fluid flow, $0.7 \mathrm{~Pa} / 1 \mathrm{~h}$ & $\mathrm{PGE}_{2}, \mathrm{COX}-2$, Nitric oxide & $\begin{array}{l}\text { Pulsating fluid flow upregulated PGE } 2 \text {, COX-2, but not COX-1 gene } \\
\text { expression (Sterck et al., 1998; Klein-Nulend et al., 1998; Joldersma et al., } \\
\text { 2000) }\end{array}$ \\
\hline
\end{tabular}

unclear. Estimates of the physiological matrix strain that is generated at the cellular level is also lacking. The strain level surrounding osteocytes is heterogeneous, amplifying the strain between the local cellular level and tissue level (Weinbaum et al., 1994; Nicolella et al., 2001; You et al., 2001; Bonivtch et al., 2007; Verbruggen et al., 2012; Hart et al., 2017). Several studies have demonstrated that variations in the size and shape of the LCN geometries are closely associated with nonuniform strain distributions (Canè et al., 1982; Metz et al., 2003). A parametric finite element model used to predict the microstructural response in lacuna showed increased strain with a decreased perilacunar tissue modulus (Bonivtch et al., 2007). The canaliculi diameter was increased by $0.8-1 \%$ in response to the applied strain and this deformation directly contributed to the enclosed dendritic process via the tethering elements (e.g., CD44, laminin, and integrins) to the canalicular wall (You et al., 2004). It is postulated that the strain difference between lacunar and canlicular structures may induce significantly different cellular responses in osteocytes (McCreadie and Hollister 1997; Nicolella et al., 2006; Verbruggen et al., 2015). In vivo studies revealed that the strain around perilacunar was an order of magnitude greater than the macroscopically applied strains, suggesting that local tissue strain can be magnified by inhomogeneous microstructural features (Nicolella et al., 2006).

There is a wide variety of potential mechanosensors present on osteocytes, which will be discussed in more detail in the following section, that transduce extracellular signals into cellular responses, including pericellular matrix, connexins/ pannexin channels, mechanically-sensitive ion channels, integrins, primary cilium, and caveolae (Figure 2) (Bonewald 2011; Qin et al., 2020). There is an ongoing debate around, whether the osteocyte's cell body or the dendritic cell processes are the primary mechanosensitive features of osteocytes. The unique dendritic morphology enables osteocytes to create a massively interconnected network in the human body creating a surface area that increases exposure to the surrounding microenvironment (Buenzli and Sims 2015; Hemmatian et al., 2017). A previous study has shown that the dendritic cell processes are more responsive to fluid shear stress than the cell body, using a transwell filter system to separate the dendritic cell processes from the cell body (Burra et al., 2010). Subsequent studies have also concluded that the more sensitive mechanotransduction occurs through dendritic cell processes, which induces calcium influx and regulate gene 


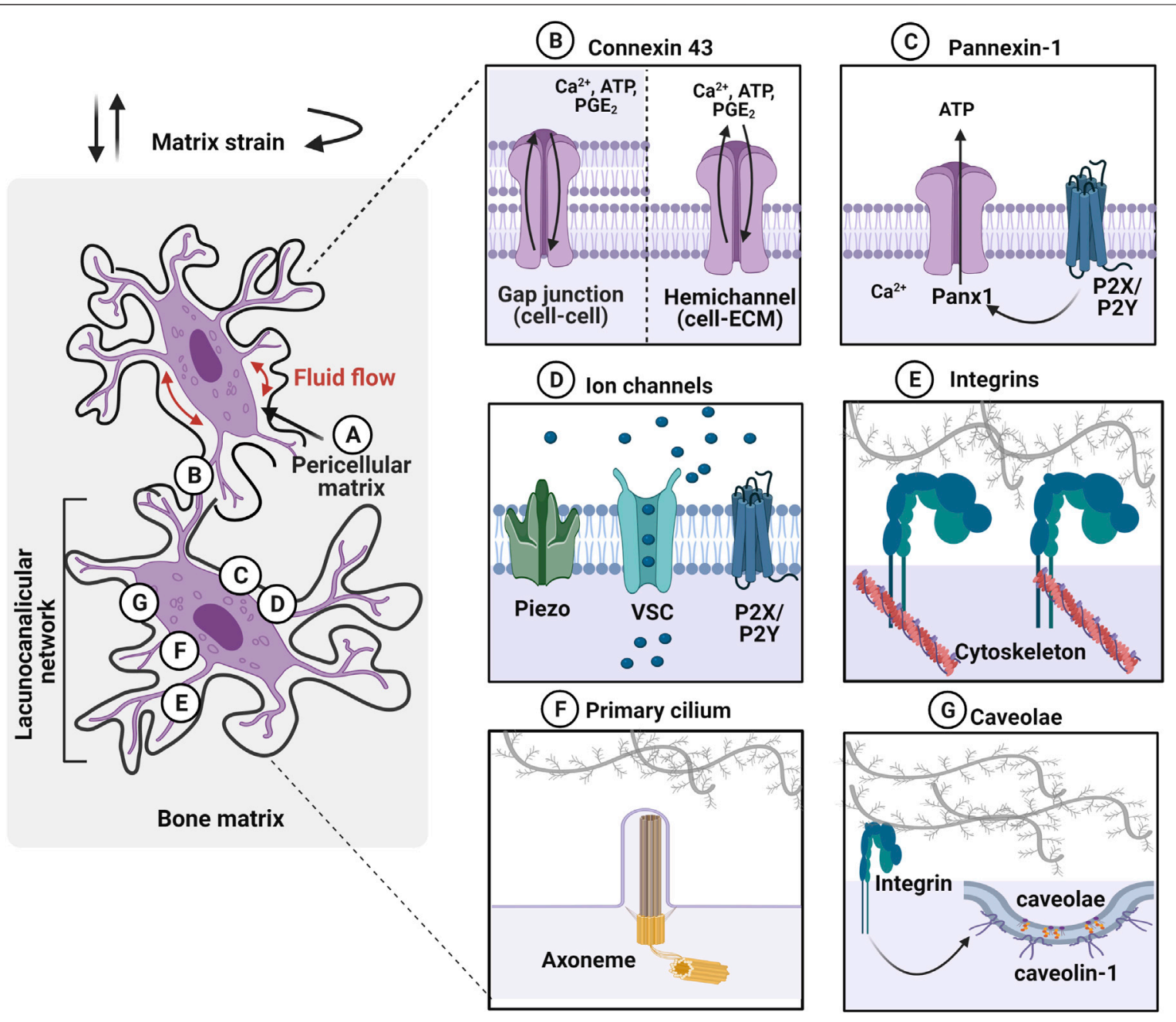

FIGURE 2 | Osteocytes within the lacunocanalicular network express mechanosensors, which can be activated by various mechanical stimuli such as fluid flow in the pericellular matrix and matrix strain (e.g., compressive, tensile, and torsional loading). (A) Osteocytes are surrounded by the pericellular matrix, between the cell and the walls of lacunae and canaliculi, which acts as a tether for osteocytes to transduce the mechanical stimulation. (B) Gap junctions, expressing on dendritic cell processes, facilitate cell-cell communication between osteocytes. Especially, connexin 43 (Cx43) is highly expressed and these junctions can also function as hemichannels that open to the microenvironment. Mechanical stimuli open these channels and transport calcium ions (Ca $\left.{ }^{2+}\right)$, adenosine triphosphate (ATP), and prostaglandin E2 $\left(\mathrm{PGE}_{2}\right)$ between cells. (C) Pannexin-1 (Panx1) hemichannels release ATP to regulate intracellular calcium levels. Panx1 is also associated with purinergic P2X7 receptor to regulate apoptosis. (D) Mechanosensing ion channels such as Piezo, voltage-sensitive calcium channel (VSC), and purinergic receptor (P2X/ P2Y) are opened in response to the mechanical stimulation and trigger calcium mobilization. (E) Integrins, transmembrane receptors that adhere cells to the extracellular matrix through specific motifs, transduce forces into cellular responses by mechanosignaling pathways. (F) Primary cilium is a protrusion of the cell membrane that is responsive to stimuli via the ciliary axoneme (microtubules). These immotile membrane protrusions act independently of intracellular $\mathrm{Ca}^{2+}$ release. (G) Caveolin-1, the structural protein of caveolae is interacting with the integrin $\beta 1$ subunit to promote mechanotransduction in osteocytes. Figure created using BioRender.

transcription of key secreted signaling molecules such as sclerostin (Wu et al., 2011; Thi et al., 2013).

\section{Pericellular Matrix}

Osteocytes are surrounded by a layer of the pericellular matrix (PCM) at the interface between the cell membrane and the hard bone matrix (Figure 2A) (Sauren et al., 1992; You et al., 2004). Although the exact composition and structure of PCM are not well defined around the osteocytes, it is considered to be comprised of collagen, fibronectin, proteoglycans, glycoproteins, hyaluronic acid and perlecan/HSPG2 (Sauren et al., 1992; You et al., 2004; Weinbaum et al., 2007;
Thompson et al., 2011a; Burra et al., 2011). It was observed that the transverse fibers span the entire PCM, which facilitate the direct interaction of osteocyte dendritic process to the canalicular wall with possible tethering molecules such as integrins, laminin, and CD44 (Noonan et al., 1996; You et al., 2004). It has been proposed that fluid drag forces transduced on the PCM via tethering molecules may induce osteocyte mechanotransduction by amplifying the strain at the cell membrane (You et al., 2001; Han et al., 2004). The strain amplification was further investigated in the context of integrin attachment points along the osteocyte dendritic processes with the collagen hillock traversing the PCM (Wang 
et al., 2007). This study demonstrated that the direct interaction of integrin promoted strain amplification by more than two orders of magnitude compared to the tissue-level strain. Hyaluronic acid has been suggested as a major component of the PCM surrounding the osteocytes (Nakamura et al., 1995; Noonan et al., 1996). This was confirmed by diminished osteocyte $\mathrm{PGE}_{2}$ release with a hyaluronidase treatment after being exposed to oscillating fluid flow under in vitro conditions (Reilly et al., 2003). The disappearance of integrin a5 was also observed with hyaluronidase treatment suggesting a tethering element of integrin is closely associated with the hyaluronic acid of PCM (Burra et al., 2011). A reduced volume of hyaluronic acid in PCM was observed with aging, which is possibly associated with the change in mechanoresponse of the osteocytes (Wang et al., 2014; Hagan et al., 2020). Perlecan, a large proteoglycan is also known to regulate solute transport and mechanosensing in PCM (Thompson et al., 2011b). Mice with perlecan deficiency showed decreased anabolic stimuli compared to the control group suggesting osteocytes experienced less fluid drag force, an effect also seen in aged mice (Wang et al., 2014).

\section{Connexin/Pannexin Channels}

Connexins are pore structure in the plasma membrane of osteocytes forming either gap junctions (cell-cell) or hemichannels (HC) (cell-matrix) (Figure 2B) (Plotkin and Bellido 2013). Although connexin 43 (Cx43) is the most highly expressed connexin in all the bone cell types, $\mathrm{Cx} 37$ has also been detected in osteocytes (Jones et al., 1993). This enables osteocytes to communicate with each other by the transfer of small molecules (less than $1 \mathrm{kD}$ ) through these gap junctions and respond to the environment via hemichannels that open to the extracellular space. Once osteocytes receive mechanical stimulation, $\mathrm{Cx} 43$ is phosphorylated, inducing the opening of connexons, six connexin subunits forming intercellular channels to regulate several effects such as influx of $\mathrm{Ca}^{2+}$, $\mathrm{ATP}$, and $\mathrm{PGE}_{2}$ from the extracellular environment (Riquelme et al., 2021; Cherian et al., 2005; Genetos et al., 2007; Cheng et al., 2001a; Riquelme and Jiang 2013). This mechanism promotes the extracellular signal-regulated kinase (ERK)1/2mitogen-activated protein kinase (MAPK) pathway, which regulates the bone remodeling process and is known to inhibit osteocyte apoptosis (Plotkin et al., 2005). Conversely, prolonged closure of connexins due to reduced mechanical loading or aging activates protein kinase B (Akt)/ P27/Caspase-3 pathway leading to apoptosis. Pannexin-1 (Panx1) is another mechanosensitive channel expressed in osteocytes that forms only non-junctional channels to exchange small molecules between cell-extracellular space in response to mechanical stimulation (Figure 2C) (Aguilar-Perez et al., 2019). During apoptosis, Panx1 channel can be activated by coupling with the purinergic receptor, $\mathrm{P} 2 \mathrm{X} 7$ to release ATP to send signals for macrophages (Sandilos et al., 2012). Panx1 knockout mouse model demonstrated that load-induced periosteal bone formation was diminished by dysregulated $\beta$-catenin and sclerostin expression in osteocytes (Seref-Ferlengez et al., 2019).

\section{Mechanically-Sensitive Ion Channels}

Mechanically-sensitive ion channels (MSICs) in osteocytes are responsive to mechanical stimulation, by opening in response to the tension created in the plasma membrane (Figure 2D) ( $\mathrm{Li}$ et al., 2019a). The role of the mechanosensing ion channel, Piezo 1, which facilitates the exchange of ions between cell and extracellular environment, and leads to the opening of voltage-sensitive calcium channels (VSCs). Osteocytes primarily express more T-type CaV3.2 VSC subunits and a relatively small amount of L-type a1 subunits, which accelerate $\mathrm{ATP} / \mathrm{Ca}^{2+}$ release in response to fluid shear stress (0.5-4 Pa) (Thompson et al., 2011a; Lu et al., 2012). Piezo 1 has been shown to not only modulate intracellular calcium levels, but also activate downstream signaling pathways such as Akt-sclerostin in response to cyclic stretch-induced mechanical stimulation. Here, sclerostin expression was downregulated by Akt phosphorylation, which was confirmed by the Piezo1 knock-out, which resulted in diminished calcium influx and Wnt, and release of ATP from the cell (Robling and Turner 2009). Osteocytes furthermore regulate mechanically induced ATP via $\mathrm{P} 2 \mathrm{X} / \mathrm{P} 2 \mathrm{Y}$ receptors leading to purinergic signaling (Li et al., 2005; Burnstock et al., 2013).

\section{Integrins}

Integrins are heterodimeric transmembrane cell receptors composed of alpha $(\alpha)$ and beta $(\beta)$ subunits that anchor cells through specific matrix motifs transducing mechanical dynamics from matrix strain and fluid-flow shear stress (Figure 2E) (Geoghegan et al., 2019). Osteocytes are known to differentially express integrins, with the a5 $\beta 1$ integrins localizing strongly on the cell body, and $\alpha \mathrm{V} \beta 3$ integrins along the dendritic cell processes, suggesting site-directed osteocyte mechanotransduction (Haugh et al., 2015; Geoghegan et al., 2019). In extracted mouse bone tissue, integrin $\alpha \mathrm{V} \beta 3$ binding was observed to localize to the canalicular wall along the periodic protrusions (McNamara et al., 2009). It is proposed that proteoglycan tethering elements bridging the dendritic process of osteocytes to the canalicular wall via integrin $\alpha \mathrm{V} \beta 3$ promotes interaction with the ECM proteins containing Arginine-GlycineAspartic acid (RGD) sequence motifs such as fibronectin, osteopontin, von Willebrand factor, sialoprotein, and thrombospondins, but not to collagen (Haugh et al., 2015). The direct adhesion between osteocyte and ECM facilitates the formation of focal adhesions, which link to the actin skeleton to activate cellular responses, such as regulating secreted signaling molecules that are guiding the effector cells. Integrins are known to recruit focal adhesion proteins, including vinculin and paxillin, which link the cytoskeleton to the ECM. Both in vivo and in vitro studies demonstrated the expression of focal adhesion proteins, such as vinculin, in osteocytes (Zhou et al., 2019; Cao et al., 2020). Another study suggested that integrin $\alpha \mathrm{V} \beta 3$-mediated mechanotransduction lacks the classic focal adhesion protein recruitment, but rather mediates $\mathrm{Ca}^{2+}$ signaling, ATP release 
TABLE 2 | The key research demonstrations for mechanosensitive signalling pathways in osteocytes and therapeutic implications.

\begin{tabular}{|c|c|c|c|}
\hline $\begin{array}{l}\text { Signalling } \\
\text { pathway }\end{array}$ & Research & Clinical implications & Reference \\
\hline Sphinogolipid & $\begin{array}{l}\text { SP1 induces osteoclast precursor migration } \\
\text { thus increase bone resorption }\end{array}$ & $\begin{array}{l}\text { Increased S1P for osteoporotic fracture/low bone } \\
\text { mineral density }\end{array}$ & $\begin{array}{l}\text { (Tian et al., 2021; Thuy et al., 2014; Zhang et al., } \\
\text { 2015) }\end{array}$ \\
\hline Wnt $/ \beta$-cat & $\begin{array}{l}\beta \text {-catenin is required for osteocyte viability } \\
\beta \text {-catenin is associate with FoxO transcription to } \\
\text { prevent osteocyte apoptosis } \\
\beta \text {-catenin binds to the connexin } 43 \text { promoters, } \\
\text { promoting cell-cell interaction and enhance the } \\
\text { viability }\end{array}$ & $\begin{array}{l}\text { Bisphosphonates, prostaglandin, estrogen are } \\
\text { known to prevent osteocyte apoptosis }\end{array}$ & $\begin{array}{l}\text { (Bellido 2014; Xia et al., 2010; Kamel et al., 2010; } \\
\text { Plotkin et al., 1999; Kitase et al., 2010; } \\
\text { Tomkinson et al., 1998; Duan and Bonewald } \\
\text { 2016; Lin et al., 2020) }\end{array}$ \\
\hline AMPK & $\begin{array}{l}\text { AMPK is the regulator for cellular energy } \\
\text { homeostasis } \\
\text { AMPK increases cellular AMP/ATP ratio helps to } \\
\text { maintain energy homeostasis } \\
\text { Protect osteocyte apoptosis by suppressing } \\
\text { oxidative stress }\end{array}$ & $\begin{array}{l}\text { Osteoporosis is possibly a disorder of energy } \\
\text { metabolism } \\
\text { AMPK can be activated by antidiabetic drugs } \\
\text { (metformin and thiazolidinediones) }\end{array}$ & $\begin{array}{l}\text { (Tong, Ganta, and Liu 2020; Jeyabalan et al., } \\
\text { 2012; Ru and Wang, 2020) }\end{array}$ \\
\hline FoxO & $\begin{array}{l}\text { FoxO activation inhibits osteocyte apoptosis } \\
\text { induced by aging and unloading } \\
\text { FoxO signalling associate with Wnt/ } \beta \text {-cat for } \\
\text { osteocyte viability }\end{array}$ & $\begin{array}{l}\text { Targeting aging-related osteoporosis/bone fragility } \\
\text { fractures } \\
\text { ROS induce apoptosis; antioxidants such as } \\
\text { polyphenols and anthocyanins through diet intake } \\
\text { induce anti-osteoclastogenic action }\end{array}$ & $\begin{array}{l}\text { (Kawata and Mikuni-Takagaki 1998; Ru and } \\
\text { Wang 2020; Domazetovic et al., 2017) }\end{array}$ \\
\hline PTH & $\begin{array}{l}\text { Activation of PTH receptor suppressed } \\
\text { sclerostin expression } \\
\text { Increased level of PTHrP activate PTH receptor } \\
\text { for anti-apoptotic effect } \\
\text { Deletion of Mef2C in osteocytes induced bone } \\
\text { formation by decreasing sclerostin; } \\
\text { PTH activates Wnt receptor, LRP6 directly, or } \\
\text { through FoxO degradation to stabilise beta- } \\
\text { catenin in Wnt signalling to induce osteogenesis }\end{array}$ & $\begin{array}{l}\text { Homologous with PTH (N-terminal 1-36) and PTH- } \\
\text { related protein (C-terminal 107-109) induce bone } \\
\text { formation and also reduce oxidative stress }\end{array}$ & $\begin{array}{l}\text { (Kamel et al., 2010; Collette et al., 2012; } \\
\text { Wysolmerski 2012; Bellido et al., 2013; Maycas } \\
\text { et al., 2015; Portal-Núñez et al., 2016) }\end{array}$ \\
\hline
\end{tabular}

and membrane potential through the purinergic channel pannexin 1, the calcium channel CaV3.2-1, and the ATP-gated purinergic receptor P2X7 (Cabahug-Zuckerman et al., 2018). Furthermore, both $\alpha 5 \beta 1$ and $\alpha \mathrm{V} \beta 3$ integrins are known to activate $\mathrm{Ca}^{2+}$ channels, but through different mechanisms. An earlier study has identified integrin $\alpha \mathrm{V} \beta 3$-specific intracellular $\mathrm{Ca}^{2+}$ signals, using a novel technique called Stokesian fluid stimulus probe (SFSP). This probe enables the application of hydrodynamic forces ( $\mathrm{pN}$ range) to the discrete location of the cell body and dendritic cell processes (Thi et al., 2013). The SFSPstimulated osteocytes (MLO-Y4) showed that dendritic cell processes were more mechanosensitive in the piconewton range of mechanical stimulation, resulting in increased levels of intracellular $\mathrm{Ca}^{2+}$. Using an integrin $\alpha \mathrm{V} \beta 3$ - specific antagonist, Integrisense 750, diminished $\mathrm{Ca}^{2+}$ response under SFSPstimulation was observed (Thi et al., 2013). Thus, integrin $\alpha \mathrm{V} \beta 3$ is not only involved in activation of focal adhesion protein-mediated mechanotransduction, but also regulates intracellular $\mathrm{Ca}^{2+}$ signals through cation and stretch-activated channels in osteocytes. Interestingly, the a5 $\beta 1$ integrins are directly associated with the opening of $\mathrm{Cx} 43 \mathrm{HC}$ to release anabolic molecules from osteocytes $\left(\mathrm{PGE}_{2}\right)$, in response to fluid shear stress (Batra et al., 2012). $\mathrm{PGE}_{2}$ also has an autocrine effect, stimulating the upregulation of $\mathrm{Cx} 43$ protein expression in osteocytes, which further induces an increase in formation of gap junctions between cells (Cheng et al., 2001b).
The activation of the intracellular mechanotransduction pathway, involving phosphoinositide 3-kinase (PI3K)-Akt signaling to open $\mathrm{Cx} 43 \mathrm{HC}$ by conformational activation of integrin $\alpha 5 \beta 1$ is independent of adhesion to the ECM. Especially, the integrin a5 subunit is crucial in establishing the specific interaction with the $\mathrm{C}$ termini of $\mathrm{Cx} 43$. It was observed that siRNA knockdown of integrin a 5 diminished the opening of the $\mathrm{Cx} 43 \mathrm{HC}$ under fluid flow-induced stimulation (Batra et al., 2012; Riquelme et al., 2021). It was argued that not only integrin a 5 activates $\mathrm{Cx} 43 \mathrm{HC}$, but also integrin $\alpha \mathrm{V} \beta 3$ expressed along the dendritic cell processes can transduce signals to the cell body for $\mathrm{Cx} 43 \mathrm{HC}$ activation via PI3K-Akt signaling. This was demonstrated both in vitro and in vivo under fluid shear stress with steady fluid flow/ oscillatory fluid flow and under tibial compression in mice. The results showed that integrin $\alpha \mathrm{V}$ was more responsive to low fluid shear stress levels to activate $\mathrm{Cx} 43 \mathrm{HC}$ compared to integrin a5 induced activation. Notably, at a higher fluid shear stress level, integrin $\alpha 5$ was activated independently of integrin $\alpha \mathrm{V}$, implying that the activation of either integrin pair is fluid shear stress level dependent. This study concluded that fluid shear stress could not suppress sclerostin expression without $\mathrm{Cx} 43 \mathrm{HC}$, which was demonstrated by blocking with antibodies, suggesting $\mathrm{Cx} 43$ is essential for the anabolic effects on bone.

Numerous in vitro studies have been undertaken to understand targeted integrin-mediated mechanotransduction in osteocytes, with only a few in vivo studies, with most of 
these using specific integrin $\beta 1$-deleted transgenic mice (Zimmerman et al., 2000; Litzenberger et al., 2009; Shekaran et al., 2014). In a study investigating the integrin $\beta 1$-mediated response after cyclic ulna loading for 3 days, osteocyte-specific integrin $\beta 1$-knockout mice showed reduced bone formation suggesting that the integrin $\beta 1$ is required to promote mechanically-induced bone formation (Litzenberger et al., 2009). Unfortunately, the osteocyte-specific integrin $\beta 3$ targeted approach has not been progressed due to technical challenges. For this reason, it is still not clear what the precise functional roles that these integrins play on bone homeostasis are.

\section{Primary Cilium}

Cilia are present in both motile and immotile cells, which have microtubule axoneme. Nine sets of microtubules doublets provide structural support and rigidity (Satir et al., 2010). The primary cilium has " $9+0$ " pattern with nine doublet microtubules without the central pair, which are seen in the immotile cilia. In contrast, " $9+2$ " pattern with 9 doublets plus one central pair of microtubules is often seen in motile cilium. Osteocytes present non-motile primary cilium with " $9+0$ " arrangement, 2-9 $\mu \mathrm{m}$ in length, which are mechanoresponsive (Figure 2F) (Qin et al., 2020). Primary cilium changes the morphology during mechanical adaptation, which induces expression of cilium-related proteins such as Sperm flagellar protein 2 (Spef2), polycystin -1 or -2 (PC1 or 2), kinesin II intraflagellar transport (Kif3a), and Adenylyl cyclase 6 (AC6) (Xiao et al., 2006; Temiyasathit et al., 2012; Qin et al., 2020). Primary cilium also changes its stiffness in response to mechanical stimulation through an acetylation-mediated mechanism that induces calcium movement. This mechanism is dependent on polycystines (polycystin 1 and 2). These are proteins located at the base of the cilium acting like a cationic change to facilitate $\mathrm{Ca}^{2+}$ transfer (Yavropoulou and Yovos 2016). Interestingly, polycystin 1 mutant mice showed reduced bone mineral density due to a lack of response to mechanical stimulation (Xiao et al., 2006). Mice also showed decreased OPG and increased RANKL levels that results in reduced bone mineral density in both trabecular and cortical bones (Temiyasathit and Jacobs 2010). The gene expression level of runt-related transcription factor 2 (Runx2), osterix, and osteocalcin were also observed to decrease, where these are all key parameters responsible for bone development, bone density, and mechanical properties.

\section{Caveolae}

Although this has been demonstrated to date only in MLO-Y4 osteocytic cells (Figure 2G), caveolin-1, the structural protein of caveolae was proposed as a membrane mechanosensor in osteocytes, interacting with the integrin $\beta 1$ subunit (Gortazar et al., 2013). Caveolae are $60-80 \mathrm{~nm}$ plasma membrane pits that are present in many mechanosensitive cells such as myocytes. In osteocytes, caveolae are physically linked to integrin $\beta 1$ leading to activation of ERK through tyrosine protein kinase ( $\mathrm{Src})$ and focal adhesion kinase (FAK) phosphorylation. Thus, it was postulated that caveolin-1 is essential for integrin/Src/ERK activation of proosteocyte survival mechanisms. This was confirmed by inhibition of caveolin-1 that diminishes anti-apoptotic effects of mechanical stimulation due to disrupted ERK activation (Plotkin et al., 2005). The detailed underlying mechanisms around the role of caveolin1 in mechanosensing in osteocytes are unclear, however, this integrin-dependent mechanism is intriguing.

\section{MECHANOTRANSDUCTION PATHWAYS IN OSTEOCYTES AND THERAPEUTIC IMPLICATIONS}

Although mechanically-induced osteocyte responses have been studied extensively, the precise signaling pathways underlying these responses are still unclear. Understanding the signaling pathways is critical due to the implications of the functional outcomes for both bone health and diseases, as well as more broadly for the other systemic role of osteocytes through their endocrine functions (Dallas et al., 2013). For the past decades, several signaling pathways have been identified, as potential therapeutic targets to improve bone health (Table 2).

\section{Sphingolipid Signaling Pathway}

In osteocyte cell models (MLO-Y4 and Ocy454 cell line), intracellular sphingosine-1-phosphatase (S1P) levels were found to be upregulated in response to fluid flow mechanical stimulation, with a corresponding downregulation of the enzymes for degradation/ dephosphorylation of S1P (Sgp11, Sgpp11), as well as upregulation of Sphk1, responsible for phosphorylation of S1P leading to its activation (Figure 3A) (Zhang et al., 2015; Dobrosak and Gooi 2017). In response to mechanical load, $\mathrm{S} 1 \mathrm{P}$ in osteocytes acts as a signaling molecule for modifying cellular $\mathrm{Ca}^{2+}$ levels and $\mathrm{PGE}_{2}$, either directly via intracellular S1P or indirectly via S1P binding to G-protein-coupled receptors (Zhang et al., 2015; Meshcheryakova et al., 2017). In response to mechanical stimulations, osteocytes modulate S1P production and secretion that facilitate paracrine osteoblast-osteoclast crosstalk. In general, osteocyte-secreted S1P plays important role in both osteoblast and osteoclast activities (Figure 3B) (Zhang et al., 2020). The newly synthesized S1P is released intracellularly and acts like a second messenger, which induces $\mathrm{Ca}^{2+}$ release in an IP3-independent manner. The extracellular S1P can also bind to G-protein-coupled receptors (S1P receptors, SIPRs), which increases the mobilization of the intracellular level of $\mathrm{Ca}^{2+}$. Furthermore, intracellular S1P can be released into circulation and binds to S1PRs on osteoblasts promoting cell differentiation and also inducing RANKL expression (Dobrosak and Gooi 2017). The osteoblast cells produce RANKL and this binds to the receptor RANK to activate osteoclasts, suggesting the crosstalk between osteoblastsosteoclasts is important to mediate the balance between bone formation and resorption. The loop of this crosstalk is regulated by osteocytes since S1P secreted by osteoclasts is released and binds to S1PRs on osteocytes in a feedback loop mechanism. The sphingolipid signaling pathway is activated 


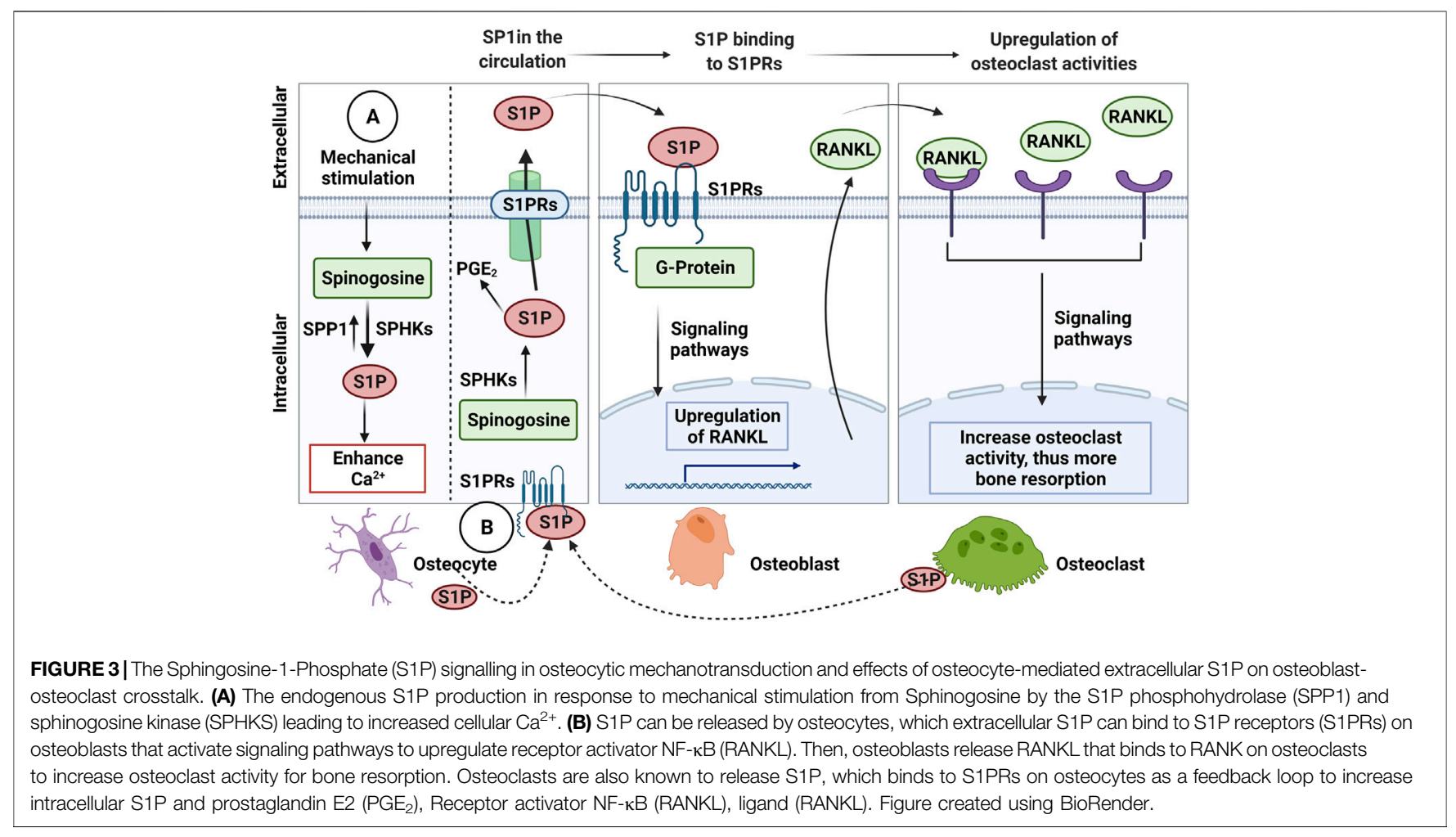

in response to oscillatory fluid flow-induced loading in bone (Figure 4A) (Tian et al., 2021; Thuy et al., 2014). The lipid mediator, S1P is the sphingolipid metabolite that acts as a signaling molecule for modifying intracellular $\mathrm{Ca}^{2+}$, which was shown in both osteoblasts and osteoclasts previously (Meshcheryakova et al., 2017).

Interestingly, the increased S1P level in blood (>200 nM) is closely associated with bone fracture risk and low bone mineral density (Lee et al., 2012). The blood S1P plasma levels have been observed to be elevated in postmenopausal women compared to premenopausal women, with the postmenopausal women known to be at higher risk of bone loss (Ardawi et al., 2018). In pathological conditions, the S1P disrupts the equilibrium between osteoblast and osteoclast activities. Increased production of S1P by osteocytes in response to mechanical stimulation may also promote the osteoblast differentiation process, which results in a decreased level of osteoblastproduced RANKL inhibiting osteoclast differentiation (Dobrosak and Gooi 2017). There are S1P-targeted therapeutic approaches for osteoporosis using S1P lyase inhibitors (e.g., CYM5520 and LX2931) and a structural analog of sphingosine (e.g., FTY720, fingolimod) (Tian et al., 2021). These pharmacological treatments increase S1P at tissue levels, inducing new bone formation, which was confirmed in ovariectomized mice and rat studies (Huang et al., 2016; Weske et al., 2019). Currently, however, it remains unclear whether the expression of S1P receptors in osteocytes has a key regulatory role in response to $\mathrm{S} 1 \mathrm{P}$ in the blood, and therefore further studies are required.

\section{TGF- $\beta$ Signaling Pathway}

TGF- $\beta$ signaling is also responsive to mechanical stimulation independent from TGF- $\beta$ receptor-induced responses, which are initiated by $S m a d 2 / 3$ phosphorylation and downregulates sclerostin (Figure 4B) (Nguyen et al., 2013). The level of Smad2/3 phosphorylation was elevated even in the presence of the TGF- $\beta$ receptor inhibitor, confirming fluid shear stress directly triggered TGF- $\beta$ signaling (Monteiro et al., 2021). Also, the level of $\operatorname{Smad} 2 / 3$ phosphorylation was larger under fluid shear stress compared to osteocytes with TGF- $\beta$ treatment, suggesting TGF- $\beta$ signaling is largely induced by fluid shear stress. Impaired TGF- $\beta$ signaling is often associated with aging, diminished mechanical adaptation and low bone mass. A recent in vivo study revealed that TGF- $\beta$ signaling is important for osteocyte functions in LCN such as PLR, as mentioned previously (Schurman et al., 2021). Deletion of this specific TGF- $\beta$ signaling compromised osteocytes functional response to mechanical stimulation, similar to that observed with aging.

\section{Wnt/ $\beta$-Catenin Signaling Pathway}

The Wnt/ $\beta$-catenin signaling has a crucial role in bone formation, not only for the effector cells but also in selfregulatory mechanisms for osteocytes (Figure 4C). Osteocytes increase the expression of the Wnt ligand in response to mechanical stimulation. Osteocyte-produced Wnt can then bind to the LRP6 receptor on osteocytes leading to intracellular $\beta$-catenin accumulation in the cytoplasm altering gene transcription changes for Wnt 


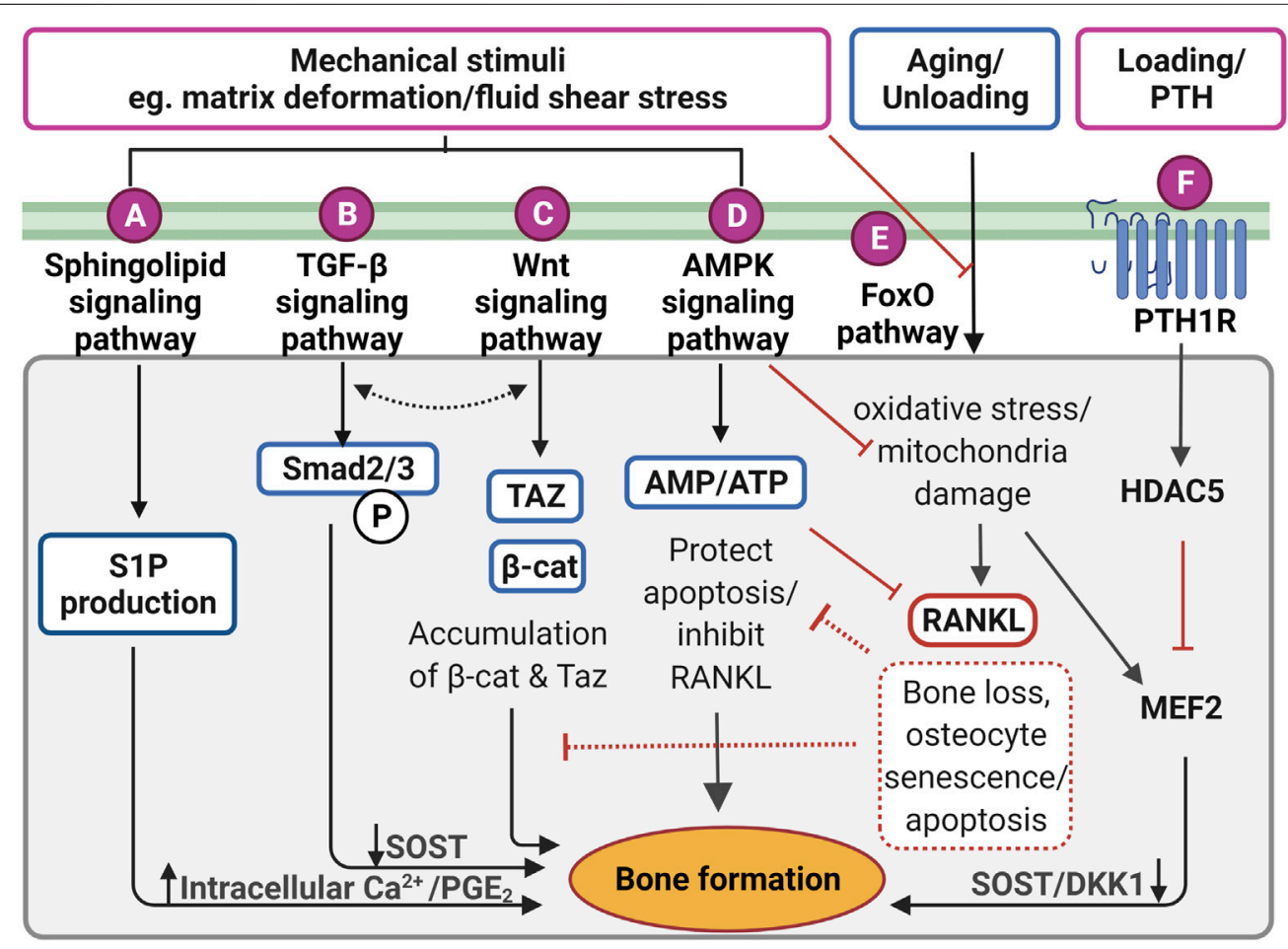

FIGURE 4 | Proposed mechanotransduction pathways in osteocytes for therapeutic targets showing intracellular signaling in response to the mechanical stimulation. (A) Pulsatile fluid flow triggered sphingolipid signaling to regulate the lipid mediators such as sphingosine-1-phosphate (S1P) production that upregulates the intracellular calcium ions $\left(\mathrm{Ca}^{2+}\right)$ levels and prostaglandin $\mathrm{E} 2\left(\mathrm{PGE}_{2}\right)$ synthesis/release in osteocytes. (B) Fluid shear stress upregulates suppressor of mothers against decapentaplegic 2/3 (Smad2/3) phosphorylation triggering transforming growth factor-beta (TGF- $\beta$ ) signaling, resulting in sclerostin (SOST) downregulation. This is independent of TGF- $\beta$ receptor-induced response. (C) Wnt/ $\beta$-catenin signaling can be elicited by direct response to extracellular matrix deformation via integrins or fluid shear stress, which is important to maintain osteocyte viability and anabolic effect by accumulating Taz and $\beta$-catenin ( $\beta$-cat). Interestingly, both TGF- $\beta$ and Wnt/ $\beta$ signaling may interact with each other to induce bone formation, however, the exact mechanism is not clear. (D) Under mechanical stimuli, adenosine monophosphate (AMP)-activated protein kinase (AMPK) signaling governs energy homeostasis in osteocytes by increasing the AMP/adenosine triphosphate (ATP) ratio for inhibiting apoptosis and decrease receptor activator of nuclear factor-kB ligand (RANKL) expression. (E) Forkhead box O (FoxO) signaling is activated to protect osteocytes from oxidative stress and mitochondria damage caused by aging and reduced mechanical stimulation. Without FoxO activation, osteocytes lead to senescence and apoptosis. (F) Parathyroid hormone receptor (PTHr) is activated both by mechanical stimulation as well as parathyroid hormone. This receptor upregulates histone deacetylase 5 (HDAC5), which inhibits myocyte enhancer factor 2 (MEF2C), responsible for negative Wnt signaling molecules, SOST and dickkopf-related protein 1 (DKK1). Figure created using BioRender.

antagonists, SOST, and DKK1 (Bonewald and Johnson 2008; Tu et al., 2015). In response to mechanical loading, the Wnt $/ \beta$-catenin signaling pathway plays an important role, not only for bone anabolic effects but also in osteocyte viability (Bonewald and Johnson 2008). Glucocorticoid treatment (dexamethasone) can cause secondary osteoporosis by inducing apoptosis in osteocytes and interestingly, this glucocorticoid-induced apoptosis can be inhibited by a steady laminar fluid shear stress of $1.6 \mathrm{~Pa}$ for $2 \mathrm{~h}$ (Kitase et al., 2010). The protective mechanism is mediated through the release of an osteocyte-produced signaling molecule called $\mathrm{PGE}_{2}$ associated with $\mathrm{Wnt} / \beta$-catenin signaling by pulsatile fluid flow shear stress $(0.2-2.4 \mathrm{~Pa}$ for $1 \mathrm{~h})$, which is independent of LRP5 receptors in osteocytes (Kamel et al., 2010). This protective effect was induced through $\mathrm{PGE}_{2}$ binding to EP2/4 receptors, which leads to Akt activation for glycogen synthesis kinase 3 (GSK-3 $\beta$ ) inhibition. This results in an accumulation of intracellular $\beta$-catenin in osteocytes. Through this process, $\mathrm{PGE}_{2}$ can also induce anabolic bone formation by crosstalk with $\mathrm{Wnt} / \beta$-catenin pathway leading to downregulation of SOST and DKK1 transcription levels and increased expression of $W n t$ in osteocytes. $\beta$-catenin is also known to bind to the $\mathrm{Cx} 43$ promoters, upregulating $C \times 43$ transcription. This enhances osteocyte cell-cell communication for osteocyte viability and increases $\mathrm{PGE}_{2}$ levels in response to steady laminar flow of $1.6 \mathrm{~Pa}$ for $2 \mathrm{~h}$ (Cherian et al., 2003; Xia et al., 2010). This mechanism is also important to the integrin $\beta 1$-caveolin-1 induced signaling, where vascular endothelial growth factor receptor 2 (VEGFR2) associated with caveolin-1 was reported to be responsive to $1 \mathrm{~Pa}$ fluid flow shear stress after $10 \mathrm{~min}$, inducing Wnt/ $\beta$-catenin signaling (de Castro et al., 2015). Another study also observed that VEGFR2 was activated by pulsatile fluid flow shear stress (1 Pa for $10 \mathrm{~min}$ ) via caveolin, which induces ERK phosphorylation leading to $\beta$-catenin translocation to the cell membrane and triggering osteocyte prosurvival signaling. The deletion of caveolin-1 by siRNA impaired VEGFR2 activation, inducing osteocyte apoptosis (Gortazar et al., 2013). 
It is known that the $\mathrm{Wnt} / \beta$-catenin signaling pathway is in crosstalk with various other signaling pathways in response to mechanical stimulations. The TGF- $\beta$ signaling pathway is known to interact with $\mathrm{Wnt} / \beta$-catenin signaling in response to mechanical stimulation (Guo and Wang 2009; Rys et al., 2016). Although the mechanism behind the association is still not fully understood, these pathways are associating at multiple hierarchical levels to regulate common target genes, such as sclerostin. This mechanism is associated with the Forkhead box $\mathrm{O}$ (FoxO) signaling pathway to inhibit osteocyte apoptosis, which will be further explained later (Manolagas and Almeida 2007). From a therapeutic perspective, Wnt/ $\beta$ catenin signaling can be induced by bisphosphonates, prostaglandin, estrogen, and anti-sclerostin antibodies, which are all known to prevent osteocyte apoptosis and have anabolic bone effects (Tomkinson et al., 1998; Plotkin et al., 1999; Kitase et al., 2010).

\section{AMPK Signaling Pathway}

RNA-sequencing analysis showed significantly up-regulated 5 'adenosine monophosphate-activated protein kinase (AMPK) signaling pathways in osteocytes under fluid shear stress (Figure 4D) (Govey et al., 2015). Prior to this study, the same group also demonstrated the rapid release of ATP in response to fluid shear stress together with up-regulation of the ATP-producing enzyme, nucleoside diphosphate kinase B (NDK), suggesting initiation of AMPK signaling to generate more ATP (Govey et al., 2014). Osteocytes have also been shown to activate AMPK signaling pathway under energy imbalance conditions, like high oxidative stress or nutrient suppression as a protective mechanism (Tong et al., 2020). AMPK is a heterotrimeric complex including $\alpha$, $\beta$, and $\gamma$ subunits. This signaling pathway can be triggered by phosphorylation of AMPK via catalytic a subunit in low energy status, which can be detected via the increased ratio of adenosine monophosphate (AMP)/ATP, by turning on ATP-producing catabolic pathways and turning off ATP-consuming anabolic pathways to restore energy (Jeyabalan et al., 2012). This process is often found in autophagy, which is a survival mechanism to prevent osteocyte apoptosis that can be found under reduced mechanical stimulation. Interestingly, it was shown that AMPK activity is associated with bone metabolism by using a 5Aminoimidazole-4-carboxyamide ribonucleotide (AICAR), an analog of AMP for AMPK activation (Yokomoto-Umakoshi et al., 2016). Osteocytes (MLO-Y4 cell line) with AICAR treatment induced the phosphorylation of AMPK a subunit leading to significantly reduced RANKL gene expression, suggesting inhibition of osteoclast activity (Yokomoto-Umakoshi et al., 2016; Tong et al., 2020). Interestingly, AMPK activation in osteocytes was found to regulate FGF23 transcription in response to mineral metabolism (Komaba 2018). For example, deficient $\mathrm{Ca}^{2+}$ stores in the endoplasmic reticulum of osteocytes stimulate storeoperated calcium entry (SOCE) via Orail on the cell membrane, which induces the influx of $\mathrm{Ca}^{2+}$ from the extracellular microenvironment leading to FGF23 transcription. Conversely, in CKD, AMPK is activated due to decreased levels of ATP, which blocks the $\mathrm{Ca}^{2+}$ influx leading to inhibition of FGF23 transcription in osteocytes leading to imbalanced serum calcium and phosphate levels. This mechanism, which still needs further investigation, may represent an important therapeutic target for CKD patients.

\section{Fox Signaling Pathway}

The protective (anti-apoptotic) action of the FoxO signaling pathway in osteocytes, as has been observed for other cell types, is also activated by mechanical stimulation (Figure 4E) (Ambrogini et al., 2010). Long-lived osteocytes experience oxidative stress and mitochondrial damage leading to apoptosis under physiological conditions such as reduced level of mechanical stimulation and aging. For example, increasing oxidative stress due to aging leads to bone loss, which is closely associated with reactive oxygen species (ROS), inhibiting the translocation of FoxO into the nucleus. However, in response to mechanical stimulation, FoxO is phosphorylated via PI3K/Akt signaling pathway, which increases $\beta$-catenin associated with the FoxO transcription factor. Osteocyte viability is important for balanced bone homeostasis as osteocyte apoptosis often leads to disease states and upregulation of bone resorption. Osteocyte apoptosis upregulates the expression of sclerostin and RANKL, promoting increased osteoclast activities (Zhang et al., 2019a). Interestingly, osteocytes located in deeper cortical bone showed abundant mitochondria with high levels of glycolytic enzymes, suggesting more protection against oxidative stress (Frikha-Benayed et al., 2016). Effective FoxO activation is closely associated with the $\mathrm{Wnt} / \beta$-catenin signaling pathway, which is also responsible for osteocyte viability (Zhang et al., 2019b). An earlier study in FoxO-deficient mice showed increased osteocyte apoptosis leading to decreased osteoblast activities, resulting in reduced bone mass in these animals (Ambrogini et al., 2010). FoxO signaling pathway represents a potential target during aging and the observed decrease in osteocyte number that occurs, potentially through the use of antioxidant supplements such as polyphenols, anthocyanins to inhibit osteocyte apoptosis (Domazetovic et al., 2017; Ru and Wang 2020).

Osteocyte-secreted sclerostin expression was once thought to be regulated only by $\mathrm{PTH}$, however, the recent findings demonstrate it is also induced by the fluid flow shear stress on osteocytes (Figure 4F) (Spatz et al., 2015; Sun et al., 2019; Sato et al., 2020). Upon stimulation, histone deacetylase 5 (HDAC5) inhibits myocyte enhancer factor 2 (MEF2C), responsible for SOST transcription in osteocytes. As expected, overexpression of HDAC5 in osteocyte cells downregulated SOST expression (Baertschi et al., 2014; Wein et al., 2015). Conversely, HDAC5 knockout mice showed an upregulation of sclerostin mRNA levels, and of the number of sclerostin-positive cells leading to a diminished $\mathrm{Wnt} / \beta$-catenin signaling pathway in osteoblasts (Wein et al., 2015).

\section{OSTEOCYTE-RELATED DISEASES AND TREATMENTS}

Abnormalities of bone strength and microstructure are common in bone diseases, where the bones become more fragile and are more likely to fracture (Feng and McDonald 2011). These disorders are often closely associated with the dysregulation of bone cells, especially osteocytes (Pathak et al., 2020). Specifically, the loss of osteocyte functional ability is linked to compromised bone 
TABLE 3 | Treatment options for osteocyte-related diseases.

\begin{tabular}{|c|c|c|}
\hline Treatment & Therapeutics & References \\
\hline Antibody treatment & $\begin{array}{l}\text { Sclerostin monoclonal antibody } \\
\text { Romosozumab (AMG 785, CDP-785), Blosozumab, and } \\
\text { BSP804 } \\
\text { DKK1 antibody (BHQ880, DKN-01) }\end{array}$ & (McClung 2017; Morrell et al., 2021) \\
\hline Bisphosphonates & $\begin{array}{l}\text { Oral bisphosphonates (Fosamax, Boniva), intravenous } \\
\text { bisphosphonates (Zoledronate, Pamidronate) }\end{array}$ & (Merlotti et al., 2007; Lewiecki 2010; Eriksen et al., 2014) \\
\hline Anti-bone resorption & $\begin{array}{l}\text { Cathepsin } \mathrm{K} \text { inhibitors (Odanacatib), and Anti-RANKL } \\
\text { (denosumab) }\end{array}$ & (Tanaka et al., 2017; Lu et al., 2018; Galvano et al., 2019) \\
\hline $\begin{array}{l}\text { Hormone replacement } \\
\text { therapy }\end{array}$ & $\begin{array}{l}\text { Estrogen receptor (Raloxifene) and parathyroid hormone } \\
\text { peptide (teriparatide, abaloparatide) }\end{array}$ & (Deal et al., 2005; Leder, 2017) \\
\hline $\begin{array}{l}\text { Non-invasive, painless } \\
\text { mechanotherapy }\end{array}$ & $\begin{array}{l}\text { Low-intensity pulsed ultrasound (LIPUS), vibration therapy, } \\
\text { whole-body vibration therapy }\end{array}$ & $\begin{array}{l}\text { (Fritton et al., 2000; Thompson et al., 2014; Thompson et al., 2016; } \\
\text { Camacho-Cardenosa et al., 2019; Jiang et al., 2019) }\end{array}$ \\
\hline
\end{tabular}

homeostasis. Osteocyte apoptosis has been proposed as a major risk factor caused by aging, reduced physical activity, hormone deficiency and inflammation resulting in dramatic decrease of osteocyte density (Almeida 2012). As a result, aged or dying cells are no longer able to carry out functional roles, which have an impact on the bone matrix quality (Shah et al., 2018). The accumulation of apoptotic osteocytes with aging is linked to several bone diseases such as osteonecrosis and the onset of age-related osteoporosis leading to increased fracture risk. During apoptosis, osteocytes secrete signals to osteoclasts to be recruited to the site for bone resorption (Schaffler et al., 2014). When apoptosis takes place, osteocytes release damage-associated molecular patterns (DAMPs) for osteoclast recruitment (McCutcheon et al., 2020). When dead osteocytes are removed, the empty lacunae are hyper-mineralized with calcium phosphate, leading to a condition called micropetrosis, resulting in more brittle bones (Qiu et al., 2002; Bell et al., 2008). The accumulation of mineralization in lacunae also interrupts the osteocytic cell-cell communication, leading to depletion of signals and nutrition due to disturbance of canalicular fluid flow (Hemmatian et al., 2017). This cascading process then inevitably further affects other osteocytes resulting in even more extensive osteocyte apoptosis. With less active osteocytes, the bone is less likely to be protected against microdamage. Microdamage triggers dying osteocytes to send signals for osteoclast activation, and at the same time, osteocytes also send anti-apoptotic factor, BAX to neighboring cells to protect their viability (Verborgt et al., 2000; Bonewald 2017). By doing this, the number of apoptotic osteocytes can be minimized around the damaged area. However, if there is a decreased number of viable cells, this mechanism is disrupted, leading to a large area of microcracks (Ma et al., 2008). Therefore, osteocyte cell viability plays a crucial role in the maintenance of bone health, and also protects against microdamage, which is a normal physiological process. The apoptosis process is closely associated with increased oxidative stress, which was confirmed with oxidative stress markers such as p53 and p66 ${ }^{\text {Shc }}$ in aged mice (Almeida et al., 2007). The oxidation process has been shown to be delayed by anti-oxidant $\mathrm{N}$-acetyl Cysteine. Another noticeable change in aged osteocytes is the decreased level of autophagic activity, which is an important indicator for stress susceptibility (Ru and Wang 2020). For example, agedosteocytes are less likely to produce autophagic proteins (e.g., Beclin-1) to suppress apoptotic proteins (e.g., cleaved-caspase-3). This mechanism is important especially for the anti-apoptotic activity of neighboring cells. However, prolonged stress will cause apoptosis eventually, which highlights the importance of the underlying mechanism between autophagy and apoptosis. Apart from aging, other factors such as estrogen deficiency and glucocorticoid treatment can also induce osteocyte apoptosis leading to osteoporosis (Jilka et al., 2013). Additionally, inflammatory cytokines such as interleukin 1 (IL1) and tumor necrosis factor-alpha (TNF- $\alpha$ ) increase osteocyte death (Marahleh et al., 2019; Wang et al., 2019). Some factors including parathyroid hormone, estrogen, bisphosphonates are known to protect osteocytes from apoptosis (Plotkin et al., 1999; Bellido and Plotkin 2011). Furthermore, as already mentioned above, unloading or decreased level of exercise often leads to decreased bone mass, which is well described in astronauts or bedridden patients (Bradbury et al., 2020; Stavnichuk et al., 2020). These findings are further illustrating, that osteocytes require mechanical stimulation, which can be introduced by mechanotherapy such as low-intensity pulsed ultrasound (LIPUS) treatments where this type of direct mechanical stimulation has been shown to improve bone healing (Thompson et al., 2016; Jiang et al., 2019). The vibration therapy studies demonstrated that high-frequency, low-magnitude vibration therapy (gravitational force $=$ acceleration of $9.81 \mathrm{~m} / \mathrm{s}^{2}$, frequency $>30 \mathrm{~Hz}$ ) improved bone health (Thompson et al., 2014). These relative parameters were estimated based on the bone dynamics that experience low-frequency $(1-3 \mathrm{~Hz})$, high-frequency $(10-50 \mathrm{~Hz})$, and large-magnitude (2,000-3,000 microstrain) (Fritton et al., 2000). Whole-body vibration (WBV) has been recently introduced as a bone stimulation therapy $(12.6 \mathrm{~Hz}$ for $30 \mathrm{~s}$ with 1 -min rest for 4 times) with hypoxic stimuli $\left(16.1 \% \mathrm{FiO}_{2}\right)$ also showed improvement in bone mineral density (BMD) after 18 weeks (Camacho-Cardenosa et al., 2019).

Osteocyte cell death with age is one of the major factors for the onset of osteoporosis. Age-related osteoporosis is closely associated with a low level of autophagic activity, which was also shown in apoptotic osteocytes. There are several treatments for osteoporosis, reducing bone resorption, that are based on the administration of oral bisphosphonates (Fosamax, Boniva), intravenous bisphosphonates (Zoledronate, Pamidronate), Cathepsin K inhibitors (Odanacatib), and Anti-RANKL antibody therapy (denosumab) (Merlotti et al., 2007; Lewiecki 2010; Eriksen et al., 2014; Suen and Qin 2016; Tanaka et al., 2017; Lu et al., 2018; Galvano et al., 2019). Osteoblast-targeted hormone replacement therapy is also widely used, including estrogen receptor (Raloxifene) and parathyroid hormone peptide (teriparatide, abaloparatide), 
however, these therapies also affect osteocytes (Deal et al., 2005; Bonewald 2017; Leder 2017). In vivo studies have confirmed that sclerostin monoclonal antibody ( $\mathrm{Scl}-\mathrm{Ab})$ treatment induced bone formation, mass, and strength (Yao et al., 2016). Scl-Ab products are commercially available including Romosozumab (AMG 785, CDP785), Blosozumab, and BSP804 (McClung 2017; Morrell et al., 2021). These antibody-based treatments are widely used for reducing fracture risk arising from various health conditions, including osteoporosis as well as post-menopause (Ominsky et al., 2011; MacNabb et al., 2016). Furthermore, a bispecific antibody for sclerostin and DKK1 has been shown to have synergistic effects for bone formation compared with monotherapies (Florio et al., 2016). These approaches try to inhibit the secretory signaling molecules produced by osteocytes that antagonize the Wntsignaling pathway in the osteoblast lineage, affecting the anabolic bone formation.

Although these treatments are widely used, the long-term safety and efficacy have to be taken into consideration. The most commonly used treatment for osteoporosis is based on bisphosphonates (Drake et al., 2008). These are effective and safe treatments with persistent benefit even after taking a break from the treatment, however, there are no clear guidelines for "drug holiday" (Diab and Watts 2013). The United States Food and Drug Administration (FDA) proposed a reevaluation of continuing bisphosphonate therapy after 3-5 years, showing a small decrease in BMD without higher fracture risk (Whitaker et al., 2012). In contrast to the prolonged half-lives of bisphosphonates, anti-RANKL (denosumab) shows reduced efficacy after treatment discontinuation (Bone et al., 2011). The anti-sclerostin treatment with romosozumab showed a decrease in BMD after discontinuation followed by 2-years treatment (McClung et al., 2018). Similarly, blosozumab treatment showed a decline in BMD in both the femoral neck and the lumbar spine after the discontinuation suggesting there is an increased risk of fracture (Recknor et al., 2015). The treatment options are summarized in Table 3.

Osteogenesis imperfect (OI) is a congenital disease that exhibits brittle bone (Basel and Steiner 2009). This disorder is caused by alterations in type I collagen that was previously known to be associated with osteoblast activities (Wenstrup et al., 1990). As the type I collagen is the predominant ECM protein, its dysregulation influences bone mineralization, leading to the impairment of local-acting growth factors such as TGF- $\beta$ (Morello 2018). A recent study revealed that the osteocyte transcriptome was dysregulated in OI mice including $\mathrm{Wnt} / \beta$ catenin and TGF- $\beta$ signaling pathways (Zimmerman et al., 2019). TGF- $\beta$ is a crucial factor to regulate bone formation and bone resorption for maintaining bone mass. However, excessive activation of the TGF- $\beta$ signaling pathway found in OI increases high bone turnover and low bone mass (Lim et al., 2017). This continuous activation of TGF- $\beta$ signaling may disrupt osteoblast functions while increasing osteocyte density. Increased TGF- $\beta$ signaling can be diminished by TGF- $\beta$ neutralizing antibody (ID11) treatment leading to improved bone mass by decreasing osteoblast and osteoclast numbers while normalizing the osteocyte density. The exact mechanism of impaired TGF- $\beta$ signaling in OI is not fully understood, but possibly through impaired binding of small leucine-rich proteoglycans (e.g., decorin) to TGF- $\beta$ in collagen fibrils. OI mouse model showed abnormalities of type I collagen expression showing abnormal osteocyte phenotype with impaired dendritic formation. Impaired osteocyte phenotype may contribute to their functional roles by interrupting the cell-matrix interaction. As a consequence, osteocytes may increase osteoblast activities towards bone formation after detecting a defective matrix, possibly for the restoration process. The osteocyte transcriptome sequencing of OI compared to wild-type control mouse models demonstrated the differential expression of dysregulated collagen fibril organization, but also impaired osteocyte dendritic formation, ECM compositions, and integrin-mediated signaling (Zimmerman et al., 2019). This observation supports the role of impaired cell-matrix interaction promoting dysregulated dendritic formation and leading to changes in functional roles. Interestingly, the Wnt signaling pathway in osteocytes was also affected in OI mice as gene levels for Wnt ligands were significantly increased, however, the exact mechanism of Wnt upregulation in OI remains unclear (Fahiminiya et al., 2013). In vivo studies with the conditional Wnt inactivation in osteocytes showed increased bone fragility and low bone mass as a result of altered Wntl production (Joeng et al., 2017). Like osteoporotic therapeutics, anti-resorptive (e.g., cathepsin $\mathrm{K}$ inhibitors and Anti-RANKLtherapies) and bone anabolic treatments (e.g., Sci-Ab and PTH) are commonly used for OI patients (Drake et al., 2008; Morello 2018).

Apart from bone-related diseases, there is more evidence emerging that osteocytes are also associated with other diseases, facilitated via secretion of the FGF23 hormone (Guo and Yuan 2015). It was reported that highly elevated circulating FGF23 is closely associated with kidney dysfunction, and this was also linked to heart failures such as left ventricular hypertrophy and vascular calcification (Faul et al., 2011; Desjardins et al., 2012). Furthermore, FGF23 was linked to chronic hypophosphatemia, caused by impaired mineralization of the bone matrix leading to bone fragility (Murali et al., 2016). Circulating FGF23 controls serum phosphate levels, by suppressing reabsorption in the kidney, and excess FGF23 causes hypophosphatemia diseases. Hypophosphatemia with high levels of FGF23, can be treated with a monoclonal FGF23 antibody (anti-FGF23), for example, burosumab, which was recently approved by the FDA to stabilize serum phosphate levels. The alternative medication for hypophosphatemia is a combination of active vitamin D and phosphate salts, however, this treatment often leads to kidney failure (Kinoshita and Fukumoto 2018; Barratt et al., 2021).

\section{DISCUSSION}

Once considered inactive cells, the osteocytes are now attributed to have crucial roles in the overall bone remodeling process, local microenvironment regulation and systemic interactions with other organs. The tightly regulated bone homeostasis becomes dysregulated as we age and with reduced mechanical stimulation, shifting the balance towards more bone resorption, leading to bone 
loss diseases such as osteopenia and osteoporosis, which increases fracture risk. As we move towards a more aging society, both intrinsic and extrinsic factors accelerate pathological signaling pathways causing disorders. Intrinsic factors (e.g., genetics, hormones, vasculature) and extrinsic factors (e.g., nutrition, physical activity, medications) are associated with the mechanisms that maintain healthy bone (Demontiero et al., 2012).

When the mechanosensitivity of osteocytes was first demonstrated, understanding the underlying modes of detection, the osteocyte-induced mechanotransduction pathways, and the functional outcomes for bone metabolism became significant research focuses in the field (Iolascon et al., 2013). The long life span of osteocytes (up to 25 years) and their important role in regulating the continuous coordinated cycle of bone formation and resorption and in the repair of bone damage makes them an ideal target for therapeutics. However, bone homeostasis is a complicated system involving multiple cell types that are signaling and coordinating each other. Until now, most studies on bone cells have focused on the more accessible effector cells, osteoblasts, and osteoclasts as compared to osteocytes (Liedert et al., 2005). The inaccessible location of osteocytes buried within the hydroxyapatite matrix, makes their visualization challenging, so studies have largely focused on in vitro cellular models to understand the mechanistic pathways that respond to mechanical stimuli.

Although in vivo studies provide more physiologically relevant outcomes, the various biological effects within more complex tissue responses are challenging to dissect and to attribute specific cellular roles given the complex microstructural organization of bone is hard to mimic. Targeting simplified approaches, focused on osteocyteelicited mechanotransduction on $2 \mathrm{D}$ plastic or $2.5 \mathrm{D}$ using collagen coating, the in vivo three-dimensionality has been largely neglected in this field. Only recently, commercially available natural (e.g., collagen and fibrin), synthetic (e.g., polyethylene glycol hydrogels), and both animal and plant-derived (e.g., matrigel, gelatin, and alginate) matrices were used to construct $3 \mathrm{D}$ in vitro models (Langhans 2018; Zhang et al., 2019c; Aziz et al., 2020). The inorganic component, hydroxyapatite, is available as a ceramic composite with tricalcium/biphasic calcium phosphate (Boukhechba et al., 2009). Hydroxyapatite is widely used for coatings on metallic implants, bone fillings, and injectable bone substitutes (Ramesh et al., 2018). Alternative synthetic material, polystyrene is also available, and is tunable for various parameters such as pore sizes and thickness (Spatz et al., 2015). Direct cell-free bone tissue also becomes an option that represents the natural milieu, but again the mechanical properties are difficult to tune (Lyons et al., 2010; Li et al., 2019b).

Despite their inherent advantages, none of the cell models recapitulates the $3 \mathrm{D}$ dendritic morphology observed in vivo, indicating more ideal matrices need to be developed. This is especially important for osteocyte mechanotransduction studies, as the dendritic morphology is now considered an important mechanotransducer. Without providing an ideal microenvironment, this is not only limiting the morphology but also cellular responses, where better understanding of osteocyte mechanotransduction will provide significant opportunities for developing novel therapeutics for bonerelated diseases.
The currently available treatments for bone disorders either target osteoclastic activity or osteoblastic activity (Rochefort 2014). Despite osteocytes abundance and their instrumental role in regulating bone metabolism, osteocyte-targeted treatments are not readily available. There are, however, some indirectly targeting antibody-based treatments to osteocyte-secreted molecules such as the recently FDA-approved sclerostin monoclonal antibody treatment for osteoporosis, promoting bone formation (Shakeri and Adanty 2020). Maintaining osteocyte viability is now considered one of the most important factors to maintain healthy bone (Bonewald 2017; Ru and Wang 2020). Aging, in particular, accelerates osteocyte apoptosis, resulting in fewer secretory factors, less bone matrix remodeling, and lower responsiveness to mechanical stimulation leading to impaired osteocyte functional roles in bone. Therefore, the development of novel osteocyte-specific therapeutics would be ideal to target osteocyte functions and signaling pathways including mechanisms to prevent apoptosis. Many of these pathways are still lacking a detailed understanding of, while others are more generic signaling pathways, such as the $\mathrm{Wnt} / \beta$ catenin and TGF- $\beta 1$ signaling, which are expressed in other cell types making therapies more challenging and less targeted (Janssens et al., 2005; Rys et al., 2016). In addition, the extraskeletal roles of osteocytes in regulating distant organs, such as kidneys, heart, and parathyroid through secreted signaling molecules provides opportunities to target the associated dysfunctions in these organs through osteocyte manipulation.

The focus of this review was to highlight the fundamental role of osteocytes, the most mechanosensitive cells of the bone, by revealing how these cells detect mechanical stimuli through various mechanosensors and the proposed mechanotransduction pathways driving the functional responses that fundamentally affect bone metabolism. However, much detail around these mechanoresponsive pathways in osteocytes is still lacking. Therefore a greater understanding of these mechanisms will help us to identify more effective treatments for both chronic bone loss diseases such as osteoporosis as well as other genetic diseases affecting bone metabolism. This will also enable researchers to unravel, how these master regulators contribute to their important extraskeletal roles.

\section{AUTHOR CONTRIBUTIONS}

Literature search was conducted by JC and AK. Manuscript writing and editing were performed by JC, AK, JL, and AR. All authors contributed intellectual property to the work, and approved for publication.

\section{FUNDING}

This work was supported by the Australian Government Research Training Program (RTP) Scholarship/The University of Queensland Scholarships (JC) and the support from Australian Research Council (AR, ARC Laureate Fellowship FL160100139, ARC Discovery Project DP190102230). 


\section{REFERENCES}

Aarden, E. M., Nijweide, P. J., van der Plas, A., Alblas, M. J., Mackie, E. J., Horton, M. A., et al. (1996). Adhesive Properties of Isolated Chick Osteocytes In Vitro. Bone 18, 305-313. doi:10.1016/8756-3282(96) 00010-5

Aguilar-Perez, A., Pacheco-Costa, R., Atkinson, E. G., Deosthale, P., Davis, H. M., Essex, A. L., et al. (2019). Age- and Sex-dependent Role of Osteocytic Pannexin1 on Bone and Muscle Mass and Strength. Sci. Rep. 9, 13903. doi:10.1038/s41598019-50444-1

Ajubi, N. E., Klein-Nulend, J., Alblas, M. J., Burger, E. H., and Nijweide, P. J. (1999). Signal Transduction Pathways Involved in Fluid Flow-Induced PGE2 Production by Cultured Osteocytes. Am. J. PhysiologyEndocrinology Metab. 276, E171-E178. doi:10.1152/ajpendo.1999.276. 1.e171

Ajubi, N. E., Klein-Nulend, J., Nijweide, P. J., Vriiheid-Lammers, T., Alblas, M. J., and Burger, E. H. (1996). Pulsating Fluid Flow Increases Prostaglandin Production by Cultured Chicken Osteocytes-A Cytoskeleton-dependent Process. Biochem. Biophysical Res. Commun. 225, 62-68. doi:10.1006/bbrc. 1996.1131

Almeida, M. (2012). Aging Mechanisms in Bone. Bonekey Rep. 1, 1. doi:10.1038/ bonekey.2012.102

Almeida, M., Han, L., Martin-Millan, M., Plotkin, L. I., Stewart, S. A., Roberson, P. K., et al. (2007). Skeletal Involution by Age-Associated Oxidative Stress and its Acceleration by Loss of Sex Steroids. J. Biol. Chem. 282, 27285-27297. doi:10. 1074/jbc.m702810200

Ambrogini, E., Almeida, M., Martin-Millan, M., Paik, J.-H., Depinho, R. A., Han, L., et al. (2010). FoxO-Mediated Defense against Oxidative Stress in Osteoblasts Is Indispensable for Skeletal Homeostasis in Mice. Cel. Metab. 11, 136-146. doi:10.1016/j.cmet. 2009.12.009

Ardawi, M.-S. M., Rouzi, A. A., Al-Senani, N. S., Qari, M. H., Elsamanoudy, A. Z., and Mousa, S. A. (2018). High Plasma Sphingosine 1-phosphate Levels Predict Osteoporotic Fractures in Postmenopausal Women: The Center of Excellence for Osteoporosis Research Study. J. Bone Metab. 25, 87-98. doi:10.11005/jbm.2018.25.2.87

Aziz, A. H., Wilmoth, R. L., Ferguson, V. L., and Bryant, S. J. (2020). IDGSW3 Osteocyte Differentiation and Bone Extracellular Matrix Deposition Are Enhanced in a 3D Matrix Metalloproteinase-Sensitive Hydrogel. ACS Appl. Bio Mater. 3, 1666-1680. doi:10.1021/acsabm. $9 \mathrm{~b} 01227$

Bach-Gansmo, F. L., Wittig, N. K., Brüel, A., Thomsen, J. S., and Birkedal, H. (2016). Immobilization and Long-Term Recovery Results in Large Changes in Bone Structure and Strength but No Corresponding Alterations of Osteocyte Lacunar Properties. Bone 91, 139-147. doi:10.1016/j.bone. 2016.07.005

Baertschi, S., Baur, N., Lueders-Lefevre, V., Voshol, J., and Keller, H. (2014). Class I and IIa Histone Deacetylases Have Opposite Effects on Sclerostin Gene Regulation. J. Biol. Chem. 289, 24995-25009. doi:10.1074/jbc.m114. 564997

Balemans, W., Van Den Ende, J., Freire Paes-Alves, A., Dikkers, F. G., Willems, P. J., Vanhoenacker, F., et al. (1999). Localization of the Gene for Sclerosteosis to the Van Buchem Disease-Gene Region on Chromosome 17q12-Q21. Am. J. Hum. Genet. 64, 1661-1669. doi:10.1086/302416

Barratt, K. R., Sawyer, R. K., Atkins, G. J., St-Arnaud, R., and Anderson, P. H. (2021). Vitamin D Supplementation Improves Bone Mineralisation Independent of Dietary Phosphate in Male X-Linked Hypophosphatemic (Hyp) Mice. Bone 143, 115767. doi:10.1016/j.bone. 2020.115767

Basel, D., and Steiner, R. D. (2009). Osteogenesis Imperfecta: Recent Findings Shed New Light on This once Well-Understood Condition. Genet. Med. 11, 375-385. doi:10.1097/gim.0b013e3181a1ff7b

Batra, N., Burra, S., Siller-Jackson, A. J., Gu, S., Xia, X., Weber, G. F., et al. (2012). Mechanical Stress-Activated Integrin 51 Induces Opening of Connexin 43 Hemichannels. Proc. Natl. Acad. Sci. 109, 3359-3364. doi:10.1073/pnas. 1115967109
Baylink, D., and Wergedal, J. (1971). Bone Formation by Osteocytes. Am. J. Physiology-Legacy Content 221, 669-678. doi:10.1152/ajplegacy.1971.221. 3.669

Bell, L. S., Kayser, M., and Jones, C. (2008). The Mineralized Osteocyte: a Living Fossil. Am. J. Phys. Anthropol. 137, 449-456. doi:10.1002/ajpa.20886

Bellido, T. (2014). Osteocyte-Driven Bone Remodeling. Calcif. Tissue Int. 94, 25-34. doi:10.1007/s00223-013-9774-y

Bellido, T., and Plotkin, L. I. (2011). Novel Actions of Bisphosphonates in Bone: Preservation of Osteoblast and Osteocyte Viability. Bone 49, 50-55. doi:10. 1016/j.bone.2010.08.008

Bellido, T., Saini, V., and Pajevic, P. D. (2013). Effects of PTH on Osteocyte Function. Bone 54, 250-257. doi:10.1016/j.bone.2012.09.016

Benedetti, M. G., Furlini, G., Zati, A., and Letizia Mauro, G. (2018). The Effectiveness of Physical Exercise on Bone Density in Osteoporotic Patients. Biomed. Res. Int. 2018, 4840531. doi:10.1155/2018/4840531

Beno, T., Yoon, Y.-J., Cowin, S. C., and Fritton, S. P. (2006). Estimation of Bone Permeability Using Accurate Microstructural Measurements. J. Biomech. 39, 2378-2387. doi:10.1016/j.jbiomech.2005.08.005

Bone, H. G., Bolognese, M. A., Yuen, C. K., Kendler, D. L., Miller, P. D., Yang, Y.-C., et al. (2011). Effects of Denosumab Treatment and Discontinuation on Bone Mineral Density and Bone Turnover Markers in Postmenopausal Women with Low Bone Mass. J. Clin. Endocrinol. Metab. 96, 972-980. doi:10.1210/jc.20101502

Bonewald, L. F., and Johnson, M. L. (2008). Osteocytes, Mechanosensing and Wnt Signaling. Bone 42, 606-615. doi:10.1016/j.bone.2007.12.224

Bonewald, L. F. (2011). The Amazing Osteocyte. J. Bone Miner. Res. 26, 229-238. doi:10.1002/jbmr.320

Bonewald, L. F. (2017). The Role of the Osteocyte in Bone and Nonbone Disease. Endocrinol. Metab. Clin. North America 46, 1-18. doi:10.1016/..ecl.2016.09.003

Bonewald, L. F., and Wacker, M. J. (2013). FGF23 Production by Osteocytes. Pediatr. Nephrol. 28, 563-568. doi:10.1007/s00467-012-2309-3

Boskey, A. L., and Coleman, R. (2010). Aging and Bone. J. Dent. Res. 89, 1333-1348. doi:10.1177/0022034510377791

Boukhechba, F., Balaguer, T., Michiels, J.-F., Ackermann, K., Quincey, D., Bouler, J.-M., et al. (2009). Human Primary Osteocyte Differentiation in a 3D Culture System. J. Bone Mineral Res. 24, 1927-1935. doi:10.1359/jbmr.090517

Bradbury, P., Wu, H., Choi, J. U., Rowan, A. E., Zhang, H., Poole, K., et al. (2020). Modeling the Impact of Microgravity at the Cellular Level: Implications for Human Disease. Front. Cel. Dev. Biol. 8, 96. doi:10.3389/fcell.2020.00096

Buenzli, P. R., and Sims, N. A. (2015). Quantifying the Osteocyte Network in the Human Skeleton. Bone 75, 144-150. doi:10.1016/j.bone.2015.02.016

Burnstock, G., Arnett, T. R., and Orriss, I. R. (2013). Purinergic Signalling in the Musculoskeletal System. Purinergic Signal. 9, 541-572. doi:10.1007/s11302013-9381-4

Burr, D. B., Milgrom, C., Fyhrie, D., Forwood, M., Nyska, M., Finestone, A., et al. (1996). In Vivo measurement of Human Tibial Strains during Vigorous Activity. Bone 18, 405-410. doi:10.1016/8756-3282(96)00028-2

Burra, S., Nicolella, D. P., Francis, W. L., Freitas, C. J., Mueschke, N. J., Poole, K., et al. (2010). Dendritic Processes of Osteocytes Are Mechanotransducers that Induce the Opening of Hemichannels. Proc. Natl. Acad. Sci. 107, 13648-13653. doi:10.1073/pnas.1009382107

Burra, S., Nicolella, D. P., and Jiang, J. X. (2011). Dark Horse in Osteocyte Biology. Communicative Integr. Biol. 4, 48-50. doi:10.4161/cib.13646

Cabahug-Zuckerman, P., Stout, R. F., Jr., Majeska, R. J., Thi, M. M., Spray, D. C., Weinbaum, S., et al. (2018). Potential Role for a Specialized $\beta 3$ Integrin-Based Structure on Osteocyte Processes in Bone Mechanosensation. J. Orthop. Res. 36, 642-652. doi:10.1002/jor.23792

Camacho-Cardenosa, M., Camacho-Cardenosa, A., Burtscher, M., Brazo-Sayavera, J., Tomas-Carus, P., Olcina, G., et al. (2019). Effects of Whole-Body Vibration Training Combined with Cyclic Hypoxia on Bone Mineral Density in Elderly People. Front. Physiol. 10, 1122. doi:10.3389/fphys.2019.01122

Candeliere, G. A., Liu, F., and Aubin, J. E. (2001). Individual Osteoblasts in the Developing Calvaria Express Different Gene Repertoires. Bone 28, 351-361. doi:10.1016/s8756-3282(01)00410-0

Canè, V., Marotti, G., Volpi, G., Zaffe, D., Palazzini, S., Remaggi, F., et al. (1982). Size and Density of Osteocyte Lacunae in Different Regions of Long Bones. Calcif. Tissue Int. 34, 558-563. doi:10.1007/BF02411304 
Cao, H., Yan, Q., Wang, D., Lai, Y., Zhou, B., Zhang, Q., et al. (2020). Focal Adhesion Protein Kindlin-2 Regulates Bone Homeostasis in Mice. Bone Res. 8, 2. doi:10.1038/s41413-019-0073-8

Chen, J. S., and Sambrook, P. N. (2011). Antiresorptive Therapies for Osteoporosis: a Clinical Overview. Nat. Rev. Endocrinol. 8, 81-91. doi:10.1038/nrendo. 2011.146

Cheng, B., Kato, Y., Zhao, S., Luo, J., Sprague, E., Bonewald, L. F., et al. (2001a). PGE2 Is Essential for Gap Junction-Mediated Intercellular Communication between Osteocyte-like MLO-Y4 Cells in Response to Mechanical Strain. Endocrinology 142, 3464-3473. doi:10.1210/endo.142.8.8338

Cheng, B., Zhao, S., Luo, J., Sprague, E., Bonewald, L. F., and Jiang, J. X. (2001b). Expression of Functional gap Junctions and Regulation by Fluid Flow in Osteocyte-like MLO-Y4 Cells. J. Bone Miner. Res. 16, 249-259. doi:10.1359/ jbmr.2001.16.2.249

Cherian, P. P., Cheng, B., Gu, S., Sprague, E., Bonewald, L. F., and Jiang, J. X. (2003). Effects of Mechanical Strain on the Function of Gap Junctions in Osteocytes Are Mediated through the Prostaglandin EP2 Receptor. J. Biol. Chem. 278, 43146-43156. doi:10.1074/jbc.m302993200

Cherian, P. P., Siller-Jackson, A. J., Gu, S., Wang, X., Bonewald, L. F., Sprague, E., et al. (2005). Mechanical Strain Opens Connexin 43 Hemichannels in Osteocytes: A Novel Mechanism for the Release of Prostaglandin. MBoC 16, 3100-3106. doi:10.1091/mbc.e04-10-0912

Clarke, B. (2008). Normal Bone Anatomy and Physiology. Clin. J. Am. Soc. Nephrol. 3 (Suppl. 3), S131-S139. doi:10.2215/CJN.04151206

Collette, N. M., Genetos, D. C., Economides, A. N., Xie, L., Shahnazari, M., Yao, W., and Loots, G. G. (2012). Targeted Deletion of Sost Distal Enhancer Increases Bone Formation and Bone Mass. Proc. Natl. Acad. Sci U. S. A. 109 (35), 14092-14097. doi:10.1073/pnas.1207188109

Creecy, A., Damrath, J. G., and Wallace, J. M. (2021). Control of Bone Matrix Properties by Osteocytes. Front. Endocrinol. 11, 578477. doi:10.3389/fendo. 2020.578477

Dai, R., Wu, Z., Chu, H. Y., Lu, J., Lyu, A., Liu, J., et al. (2020). Cathepsin K: The Action in and beyond Bone. Front. Cel. Dev. Biol. 8, 433. doi:10.3389/fcell.2020. 00433

Dallas, S. L., Prideaux, M., and Bonewald, L. F. (2013). The Osteocyte: An Endocrine Cell $\ldots$ and More. Endocr. Rev. 34, 658-690. doi:10.1210/er. 2012-1026

Day, T. F., Guo, X., Garrett-Beal, L., and Yang, Y. (2005). Wnt/ $\beta$-Catenin Signaling in Mesenchymal Progenitors Controls Osteoblast and Chondrocyte Differentiation during Vertebrate Skeletogenesis. Developmental Cel. 8, 739-750. doi:10.1016/j.devcel.2005.03.016

de Castro, L. F., Maycas, M., Bravo, B., Esbrit, P., and Gortazar, A. (2015). VEGF Receptor 2 (VEGFR2) Activation Is Essential for Osteocyte Survival Induced by Mechanotransduction. J. Cel. Physiol. 230, 278-285. doi:10.1002/jcp.24734

Deal, C., Omizo, M., Schwartz, E. N., Eriksen, E. F., Cantor, P., Wang, J., et al. (2005). Combination Teriparatide and Raloxifene Therapy for Postmenopausal Osteoporosis: Results from a 6-Month Double-Blind Placebo-Controlled Trial. J. Bone Miner Res. 20, 1905-1911. doi:10.1359/jbmr.050714

Demontiero, O., Vidal, C., and Duque, G. (2012). Aging and Bone Loss: New Insights for the Clinician. Ther. Adv. Musculoskelet. 4, 61-76. doi:10.1177/ 1759720x11430858

Denisov-Nikol'skiĭ, Iu. I., and Doktorov, A. A. (1987). Spatial Organization of the Lacunar-Canalicular System in the Structures of Bone Lamellae. Arkh Anat. Gistol. Embriol. 93, 37-43.

Desjardins, L., Liabeuf, S., Liabeuf, S., Renard, C., Lenglet, A., Lemke, H.-D., et al. (2012). FGF23 Is Independently Associated with Vascular Calcification but Not Bone mineral Density in Patients at Various CKD Stages. Osteoporos. Int. 23, 2017-2025. doi:10.1007/s00198-011-1838-0

Diab, D. L., and Watts, N. B. (2013). Bisphosphonate Drug holiday: Who, when and How Long. Ther. Adv. Musculoskelet. 5, 107-111. doi:10.1177/ $1759720 \times 13477714$

Dobrosak, C., and Gooi, J. H. (2017). Increased Sphingosine-1-Phosphate Production in Response to Osteocyte Mechanotransduction. Bone Rep. 7, 114-120. doi:10.1016/j.bonr.2017.10.002

Dole, N. S., Mazur, C. M., Acevedo, C., Lopez, J. P., Monteiro, D. A., Fowler, T. W., et al. (2017). Osteocyte-Intrinsic TGF- $\beta$ Signaling Regulates Bone Quality through Perilacunar/Canalicular Remodeling. Cel. Rep. 21, 2585-2596. doi:10.1016/j.celrep.2017.10.115
Domazetovic, V., Marcucci, G., Iantomasi, T., Brandi, M. L., and Vincenzini, M. T. (2017). Oxidative Stress in Bone Remodeling: Role of Antioxidants. ccmbm 14, 209-216. doi:10.11138/ccmbm/2017.14.1.209

Drake, M. T., Clarke, B. L., and Khosla, S. (2008). Bisphosphonates: Mechanism of Action and Role in Clinical Practice. Mayo Clinic Proc. 83, 1032-1045. doi:10. 4065/83.9.1032

Duan, P., and Bonewald, L. F. (2016). The Role of the Wnt/ $\beta$-Catenin Signaling Pathway in Formation and Maintenance of Bone and Teeth. Int. J. Biochem. Cel. Biol. 77, 23-29. doi:10.1016/j.biocel.2016.05.015

Dussold, C., Gerber, C., White, S., Wang, X., Qi, L., Francis, C., et al. (2019). DMP1 Prevents Osteocyte Alterations, FGF23 Elevation and Left Ventricular Hypertrophy in Mice with Chronic Kidney Disease. Bone Res. 7, 12. doi:10. 1038/s41413-019-0051-1

Eriksen, E. F., Díez-Pérez, A., and Boonen, S. (2014). Update on Long-Term Treatment with Bisphosphonates for Postmenopausal Osteoporosis: A Systematic Review. Bone 58, 126-135. doi:10.1016/j.bone.2013.09.023

Fahiminiya, S., Majewski, J., Mort, J., Moffatt, P., Glorieux, F. H., and Rauch, F. (2013). Mutations in WNT1 Are a Cause of Osteogenesis Imperfecta. J. Med. Genet. 50, 345-348. doi:10.1136/jmedgenet-2013-101567

Faibish, D., Ott, S. M., and Boskey, A. L. (2006). Mineral Changes in Osteoporosis. Clin. Orthop. Relat. Res. 443, 28-38. doi:10.1097/01.blo.0000200241.14684.4e

Faul, C., Amaral, A. P., Oskouei, B., Hu, M.-C., Sloan, A., Isakova, T., et al. (2011). FGF23 Induces Left Ventricular Hypertrophy. J. Clin. Invest. 121, 4393-4408. doi:10.1172/jci46122

Feng, X., and McDonald, J. M. (2011). Disorders of Bone Remodeling. Annu. Rev. Pathol. Mech. Dis. 6, 121-145. doi:10.1146/annurev-pathol-011110-130203

Florencio-Silva, R., Sasso, G. R., Sasso-Cerri, E., Simões, M. J., and Cerri, P. S. (2015). Biology of Bone Tissue: Structure, Function, and Factors that Influence Bone Cells. Biomed. Res. Int. 2015, 421746. doi:10.1155/2015/421746

Florio, M., Gunasekaran, K., Stolina, M., Li, X., Liu, L., Tipton, B., et al. (2016). A Bispecific Antibody Targeting Sclerostin and DKK-1 Promotes Bone Mass Accrual and Fracture Repair. Nat. Commun. 7, 11505. doi:10.1038/ ncomms 11505

Frikha-Benayed, D., Basta-Pljakic, J., Majeska, R. J., and Schaffler, M. B. (2016). Regional Differences in Oxidative Metabolism and Mitochondrial Activity Among Cortical Bone Osteocytes. Bone 90, 15-22. doi:10.1016/j.bone.2016. 05.011

Fritton, S. P., J. McLeod, K., and Rubin, C. T. (2000). Quantifying the Strain History of Bone: Spatial Uniformity and Self-Similarity of Low-Magnitude Strains. J. Biomech. 33, 317-325. doi:10.1016/s0021-9290(99)00210-9

Galvano, A., Scaturro, D., Badalamenti, G., Incorvaia, L., Rizzo, S., Castellana, L., et al. (2019). Denosumab for Bone Health in Prostate and Breast Cancer Patients Receiving Endocrine Therapy? A Systematic Review and a MetaAnalysis of Randomized Trials. J. Bone Oncol. 18, 100252. doi:10.1016/j.jbo. 2019.100252

Gardinier, J. D., Al-Omaishi, S., Morris, M. D., and Kohn, D. H. (2016). PTH Signaling Mediates Perilacunar Remodeling during Exercise. Matrix Biol. 52-54, 162-175. doi:10.1016/j.matbio.2016.02.010

Gaur, T., Lengner, C. J., Hovhannisyan, H., Bhat, R. A., Bodine, P. V. N., Komm, B. S., et al. (2005). Canonical WNT Signaling Promotes Osteogenesis by Directly Stimulating Runx2 Gene Expression. J. Biol. Chem. 280, 33132-33140. doi:10. 1074/jbc.m500608200

Genetos, D. C., Kephart, C. J., Zhang, Y., Yellowley, C. E., and Donahue, H. J. (2007). Oscillating Fluid Flow Activation of gap junction Hemichannels Induces Atp Release from MLO-Y4 Osteocytes. J. Cel. Physiol. 212, 207-214. doi:10.1002/jcp.21021

Geoghegan, I. P., Hoey, D. A., and McNamara, L. M. (2019). Integrins in Osteocyte Biology and Mechanotransduction. Curr. Osteoporos. Rep. 17, 195-206. doi:10. 1007/s11914-019-00520-2

Gerbaix, M., Gnyubkin, V., Farlay, D., Olivier, C., Ammann, P., Courbon, G., et al. (2017). One-month Spaceflight Compromises the Bone Microstructure, TissueLevel Mechanical Properties, Osteocyte Survival and Lacunae Volume in Mature Mice Skeletons. Sci. Rep. 7, 2659. doi:10.1038/s41598-017-03014-2

Gluhak-Heinrich, J., Pavlin, D., Yang, W., MacDougall, M., and Harris, S. E. (2007). MEPE Expression in Osteocytes during Orthodontic Tooth Movement. Arch. Oral Biol. 52, 684-690. doi:10.1016/j.archoralbio.2006.12.010

Goldring, S. R. (2015). The Osteocyte: Key Player in Regulating Bone Turnover. RMD Open 1, e000049. doi:10.1136/rmdopen-2015-000049 
Gortazar, A. R., Martin-Millan, M., Bravo, B., Plotkin, L. I., and Bellido, T. (2013). Crosstalk between Caveolin-1/Extracellular Signal-Regulated Kinase (ERK) and $\beta$-Catenin Survival Pathways in Osteocyte Mechanotransduction. J. Biol. Chem. 288, 8168-8175. doi:10.1074/jbc.m112.437921

Govey, P. M., Jacobs, J. M., Tilton, S. C., Loiselle, A. E., Zhang, Y., Freeman, W. M., et al. (2014). Integrative Transcriptomic and Proteomic Analysis of Osteocytic Cells Exposed to Fluid Flow Reveals Novel Mechano-Sensitive Signaling Pathways. J. Biomech. 47, 1838-1845. doi:10.1016/j.jbiomech.2014.03.022

Govey, P. M., Kawasawa, Y. I., and Donahue, H. J. (2015). Mapping the Osteocytic Cell Response to Fluid Flow Using RNA-Seq. J. Biomech. 48, 4327-4332. doi:10. 1016/j.jbiomech.2015.10.045

Guo, X., and Wang, X.-F. (2009). Signaling Cross-Talk between TGF- $\beta /$ BMP and Other Pathways. Cell Res. 19, 71-88. doi:10.1038/cr.2008.302

Guo, Y.-C., and Yuan, Q. (2015). Fibroblast Growth Factor 23 and Bone Mineralisation. Int. J. Oral Sci. 7, 8-13. doi:10.1038/ijos.2015.1

Hagan, M. L., Yu, K., Zhu, J., Vinson, B. N., Roberts, R. L., Montesinos Cartagena, M., et al. (2020). Decreased Pericellular Matrix Production and Selection for Enhanced Cell Membrane Repair May Impair Osteocyte Responses to Mechanical Loading in the Aging Skeleton. Aging Cell 19, e13056. doi:10.1111/acel.13056

Han, Y., Cowin, S. C., Schaffler, M. B., and Weinbaum, S. (2004). Mechanotransduction and Strain Amplification in Osteocyte Cell Processes. Proc. Natl. Acad. Sci. 101, 16689-16694. doi:10.1073/pnas.0407429101

Harris, S. E., Gluhak-Heinrich, J., Harris, M. A., Yang, W., Bonewald, L. F., Riha, D., et al. (2007). DMP1 and MEPE Expression Are Elevated in Osteocytes after Mechanical Loading In Vivo: Theoretical Role in Controlling mineral Quality in the Perilacunar Matrix. J. Musculoskelet. Neuronal Interact 7, 313-315.

Hart, N. H., Nimphius, S., Rantalainen, T., Ireland, A., Siafarikas, A., and Newton, R. U. (2017). Mechanical Basis of Bone Strength: Influence of Bone Material, Bone Structure and Muscle Action. J. Musculoskelet. Neuronal Interact 17, 114-139.

Haugh, M. G., Vaughan, T. J., and McNamara, L. M. (2015). The Role of Integrin $\alpha \mathrm{V} \beta 3$ in Osteocyte Mechanotransduction. J. Mech. Behav. Biomed. Mater. 42, 67-75. doi:10.1016/j.jmbbm.2014.11.001

Hellmich, C., and Ulm, F.-J. (2002). Micromechanical Model for Ultrastructural Stiffness of Mineralized Tissues. J. Eng. Mech. 128, 898-908. doi:10.1061/(asce) 0733-9399(2002)128:8(898)

Hemmatian, H., Bakker, A. D., Klein-Nulend, J., and van Lenthe, G. H. (2017). Aging, Osteocytes, and Mechanotransduction. Curr. Osteoporos. Rep. 15, 401-411. doi:10.1007/s11914-017-0402-z

Huang, C., Ling, R., Li, F.-J., Li, E.-C., Huang, Q.-K., Liu, B.-G., et al. (2016). FTY720 Enhances Osteogenic Differentiation of Bone Marrow Mesenchymal Stem Cells in Ovariectomized Rats. Mol. Med. Rep. 14, 927-935. doi:10.3892/ mmr.2016.5342

Iolascon, G., Resmini, G., and Tarantino, U. (2013). Mechanobiology of Bone. Aging Clin. Exp. Res. 25 (Suppl. 1), S3-S7. doi:10.1007/s40520-013-0101-2

Jacobs, C. R., Temiyasathit, S., and Castillo, A. B. (2010). Osteocyte Mechanobiology and Pericellular Mechanics. Annu. Rev. Biomed. Eng. 12, 369-400. doi:10.1146/annurev-bioeng-070909-105302

Jähn, K., Kelkar, S., Zhao, H., Xie, Y., Tiede-Lewis, L. M., Dusevich, V., et al. (2017). 'Osteocytes Acidify Their Microenvironment in Response to PTHrP In Vitro and in Lactating Mice In Vivo. J. Bone Miner. Res. 32, 1761-1772.

Janssens, K., ten Dijke, P., Janssens, S., and Van Hul, W. (2005). Transforming Growth Factor-B1 to the Bone. Endocr. Rev. 26, 743-774. doi:10.1210/er.20040001

Jeyabalan, J., Shah, M., Viollet, B., and Chenu, C. (2012). AMP-activated Protein Kinase Pathway and Bone Metabolism. J. Endocrinol. 212, 277-290. doi:10. 1530/joe-11-0306

Jiang, X., Savchenko, O., Li, Y., Qi, S., Yang, T., Zhang, W., et al. (2019). A Review of Low-Intensity Pulsed Ultrasound for Therapeutic Applications. IEEE Trans. Biomed. Eng. 66, 2704-2718. doi:10.1109/tbme.2018.2889669

Jilka, R. L., Noble, B., and Weinstein, R. S. (2013). Osteocyte Apoptosis. Bone 54, 264-271. doi:10.1016/j.bone.2012.11.038

Joeng, K. S., Lee, Y.-C., Lim, J., Chen, Y., Jiang, M.-M., Munivez, E., et al. (2017). Osteocyte-specific WNT1 Regulates Osteoblast Function during Bone Homeostasis. J. Clin. Invest. 127, 2678-2688. doi:10.1172/jci92617

Johnson, M. W. (1984). Behavior of Fluid in Stressed Bone and Cellular Stimulation. Calcif. Tissue Int. 36, S72-S76. doi:10.1007/bf02406137
Joldersma, M., Burger, E. H., Semeins, C. M., and Klein-Nulend, J. (2000). Mechanical Stress Induces COX-2 mRNA Expression in Bone Cells from Elderly Women. J. Biomech. 33, 53-61. doi:10.1016/s0021-9290(99)00172-4

Jones, S. J., Gray, C., Sakamaki, H., Arora, M., Boyde, A., Gourdie, R., et al. (1993). The Incidence and Size of gap Junctions between the Bone Cells in Rat Calvaria. Anat. Embryol. (Berl) 187, 343-352. doi:10.1007/BF00185892

Kamel, M. A., Picconi, J. L., Lara-Castillo, N., and Johnson, M. L. (2010). Activation of $\beta$-catenin Signaling in MLO-Y4 Osteocytic Cells versus 2T3 Osteoblastic Cells by Fluid Flow Shear Stress and PGE2: Implications for the Study of Mechanosensation in Bone. Bone 47, 872-881. doi:10.1016/j. bone.2010.08.007

Kamel-ElSayed, S. A., Tiede-Lewis, L. M., Lu, Y., Veno, P. A., and Dallas, S. L. (2015). Novel Approaches for Two and Three Dimensional Multiplexed Imaging of Osteocytes. Bone 76, 129-140. doi:10.1016/j. bone.2015.02.011

Karner, C. M., and Long, F. (2017). Wnt Signaling and Cellular Metabolism in Osteoblasts. Cell. Mol. Life Sci. 74, 1649-1657. doi:10.1007/s00018-0162425-5

Kawata, A., and Mikuni-Takagaki, Y. (1998). Mechanotransduction in Stretched Osteocytes-Temporal Expression of Immediate Early and Other Genes. Biochem. Biophys. Res. Commun. 246 (2), 404-408. doi:10.1006/bbrc.1998.8632

Kearns, A. E., Khosla, S., and Kostenuik, P. J. (2008). Receptor Activator of Nuclear Factor $\mathrm{\kappa B}$ Ligand and Osteoprotegerin Regulation of Bone Remodeling in Health and Disease. Endocr. Rev. 29, 155-192. doi:10. 1210/er.2007-0014

Kegelman, C. D., Coulombe, J. C., Jordan, K. M., Horan, D. J., Qin, L., Robling, A. G., et al. (2020). YAP and TAZ Mediate Osteocyte Perilacunar/ Canalicular Remodeling. J. Bone Miner. Res. 35, 196-210. doi:10.1002/ jbmr.3876

Kinoshita, Y., and Fukumoto, S. (2018). X-linked Hypophosphatemia and FGF23Related Hypophosphatemic Diseases: Prospect for New Treatment. Endocr. Rev. 39, 274-291. doi:10.1210/er.2017-00220

Kitase, Y., Barragan, L., Qing, H., Kondoh, S., Jiang, J. X., Johnson, M. L., et al. (2010). Mechanical Induction of PGE2 in Osteocytes Blocks GlucocorticoidInduced Apoptosis through Both the $\beta$-catenin and PKA Pathways. J. Bone Miner. Res. 25, 2657-2668. doi:10.1002/jbmr.168

Klein-Nulend, J., Burger, E. H., Semeins, C. M., Raisz, L. G., and Pilbeam, C. C. (1997). Pulsating Fluid Flow Stimulates Prostaglandin Release and Inducible Prostaglandin G/H Synthase mRNA Expression in Primary Mouse Bone Cells. J. Bone Miner. Res. 12, 45-51. doi:10.1359/jbmr.1997.12.1.45

Kogawa, M., Khalid, K. A., Wijenayaka, A. R., Ormsby, R. T., Evdokiou, A., Anderson, P. H., et al. (2018). Recombinant Sclerostin Antagonizes Effects of Ex Vivo Mechanical Loading in Trabecular Bone and Increases Osteocyte Lacunar Size. Am. J. Physiology-Cell Physiol. 314, C53-c61. doi:10.1152/ajpcell.00175. 2017

Kogawa, M., Wijenayaka, A. R., Ormsby, R. T., Thomas, G. P., Anderson, P. H., Bonewald, L. F., et al. (2013). Sclerostin Regulates Release of Bone mineral by Osteocytes by Induction of Carbonic Anhydrase 2. J. Bone Miner. Res. 28, 2436-2448. doi:10.1002/jbmr.2003

Kohn, D. H., Sahar, N. D., Wallace, J. M., Golcuk, K., and Morris, M. D. (2009). Exercise Alters Mineral and Matrix Composition in the Absence of Adding New Bone. Cells Tissues Organs 189, 33-37. doi:10.1159/000151452

Komaba, H. (2018). Energy Sensor as a New Regulator of FGF23 Synthesis. Kidney Int. 94, 453-455. doi:10.1016/j.kint.2018.05.008

Krajisnik, T., Björklund, P., Marsell, R., Ljunggren, O., Akerström, G., Jonsson, K. B., et al. (2007). Fibroblast Growth Factor-23 Regulates Parathyroid Hormone and 1 $\alpha$-Hydroxylase Expression in Cultured Bovine Parathyroid Cells. J. Endocrinol. 195, 125-131. doi:10.1677/joe-07-0267

Kulkarni, R. N., Bakker, A. D., Everts, V., and Klein-Nulend, J. (2010). Inhibition of Osteoclastogenesis by Mechanically Loaded Osteocytes: Involvement of MEPE. Calcif. Tissue Int. 87, 461-468. doi:10.1007/s00223-010-9407-7

Langhans, S. A. (2018). Three-Dimensional In Vitro Cell Culture Models in Drug Discovery and Drug Repositioning. Front. Pharmacol. 9, 6. doi:10.3389/fphar. 2018.00006

Leder, B. Z. (2017). Parathyroid Hormone and Parathyroid Hormone-Related Protein Analogs in Osteoporosis Therapy. Curr. Osteoporos. Rep. 15, 110-119. doi:10.1007/s11914-017-0353-4 
Lee, S. H., Lee, S.-Y., Lee, Y.-S., Kim, B.-J., Lim, K.-H., Cho, E.-H., et al. (2012). Higher Circulating Sphingosine 1-Phosphate Levels Are Associated with Lower Bone Mineral Density and Higher Bone Resorption Marker in Humans. J. Clin. Endocrinol. Metab. 97, E1421-E1428. doi:10.1210/jc.2012-1044

Lewiecki, E. M. (2010). Bisphosphonates for the Treatment of Osteoporosis: Insights for Clinicians. Ther. Adv. Chronic Dis. 1, 115-128. doi:10.1177/ 2040622310374783

Li, J., Liu, D., Ke, H. Z., Duncan, R. L., and Turner, C. H. (2005). The P2X7 Nucleotide Receptor Mediates Skeletal Mechanotransduction. J. Biol. Chem. 280, 42952-42959. doi:10.1074/jbc.m506415200

Li, J., Rose, E., Frances, D., Sun, Y., and You, L. (2012). Effect of Oscillating Fluid Flow Stimulation on Osteocyte mRNA Expression. J. Biomech. 45, 247-251. doi:10.1016/j.jbiomech.2011.10.037

Li, J., Sarosi, I., Cattley, R. C., Pretorius, J., Asuncion, F., Grisanti, M., et al. (2006). Dkk1-mediated Inhibition of Wnt Signaling in Bone Results in Osteopenia. Bone 39, 754-766. doi:10.1016/j.bone.2006.03.017

Li, L., Lu, H., Zhao, Y., Luo, J., Yang, L., Liu, W., et al. (2019a). Functionalized Cellfree Scaffolds for Bone Defect Repair Inspired by Self-Healing of Bone Fractures: A Review and New Perspectives. Mater. Sci. Eng. C 98, 1241-1251. doi:10.1016/j.msec.2019.01.075

Li, M. C. M., Chow, S. K. H., Wong, R. M. Y., Qin, L., and Cheung, W. H. (2021). The Role of Osteocytes-specific Molecular Mechanism in Regulation of Mechanotransduction - A Systematic Review. J. Orthopaedic Translation 29, 1-9. doi:10.1016/j.jot.2021.04.005

Li, X., Han, L., Nookaew, I., Mannen, E., Silva, M. J., Almeida, M., et al. (2019b). 'Stimulation of Piezo1 by Mechanical Signals Promotes Bone Anabolism. Elife 8, 1. doi:10.7554/elife.49631

Liedert, A., Kaspar, D., Augat, P., Ignatius, A., and Claes, L. (2005). "Mechanobiology of Bone Tissue and Bone Cells," in Mechanosensitivity in Cells and Tissues. Editors A. Kamkin and I. Kiseleva (Moscow: Academia Publishing House Ltd.).

Lim, J., Grafe, I., Alexander, S., and Lee, B. (2017). Genetic Causes and Mechanisms of Osteogenesis Imperfecta. Bone 102, 40-49. doi:10.1016/j. bone.2017.02.004

Lin, X., Patil, S., Gao, Y.-G., and Qian, A. (2020). The Bone Extracellular Matrix in Bone Formation and Regeneration. Front. Pharmacol. 11, 757. doi:10.3389/ fphar.2020.00757

Litzenberger, J. B., Kim, J.-B., Tummala, P., and Jacobs, C. R. (2010). $\beta 1$ Integrins Mediate Mechanosensitive Signaling Pathways in Osteocytes. Calcif. Tissue Int. 86, 325-332. doi:10.1007/s00223-010-9343-6

Litzenberger, J. B., Tang, W. J., Castillo, A. B., and Jacobs, C. R. (2009). Deletion of $\beta 1$ Integrins from Cortical Osteocytes Reduces Load-Induced Bone Formation. Cel. Mol. Bioeng. 2, 416-424. doi:10.1007/s12195-0090068-4

Lotinun, S., Ishihara, Y., Nagano, K., Kiviranta, R., Carpentier, V. T., Neff, L., et al. (2019). Cathepsin K-Deficient Osteocytes Prevent Lactation-Induced Bone Loss and Parathyroid Hormone Suppression. J. Clin. Invest. 129, 3058-3071. doi:10.1172/jci122936

Lu, J., Wang, M., Wang, Z., Fu, Z., Lu, A., and Zhang, G. (2018). Advances in the Discovery of Cathepsin K Inhibitors on Bone Resorption. J. Enzyme Inhib. Med. Chem. 33, 890-904. doi:10.1080/14756366.2018.1465417

Lu, X. L., Huo, B., Chiang, V., and Guo, X. E. (2012). Osteocytic Network Is More Responsive in Calcium Signaling Than Osteoblastic Network under Fluid Flow. J. Bone Miner. Res. 27, 563-574. doi:10.1002/jbmr.1474

Lyons, F. G., Al-Munajjed, A. A., Kieran, S. M., Toner, M. E., Murphy, C. M., Duffy, G. P., et al. (2010). The Healing of Bony Defects by Cell-free Collagen-Based Scaffolds Compared to Stem Cell-Seeded Tissue Engineered Constructs. Biomaterials 31, 9232-9243. doi:10.1016/j. biomaterials.2010.08.056

Ma, Y.-L., Dai, R.-C., Sheng, Z.-F., Jin, Y., Zhang, Y.-H., Fang, L.-N., et al. (2008). Quantitative Associations between Osteocyte Density and Biomechanics, Microcrack and Microstructure in OVX Rats Vertebral Trabeculae. J. Biomech. 41, 1324-1332. doi:10.1016/j.jbiomech.2008.01.017

MacNabb, C., Patton, D., and Hayes, J. S. (20162016). Sclerostin Antibody Therapy for the Treatment of Osteoporosis: Clinical Prospects and Challenges. J. Osteoporos. 2016, 6217286. doi:10.1155/2016/6217286

Manolagas, S. C., and Almeida, M. (2007). Gone with the Wnts: $\beta$-Catenin, T-Cell Factor, Forkhead Box O, and Oxidative Stress in Age-dependent Diseases of
Bone, Lipid, and Glucose Metabolism. Mol. Endocrinol. 21, 2605-2614. doi:10. 1210/me.2007-0259

Marahleh, A., Kitaura, H., Ohori, F., Kishikawa, A., Ogawa, S., Shen, W.-R., et al. (2019). TNF- $\alpha$ Directly Enhances Osteocyte RANKL Expression and Promotes Osteoclast Formation. Front. Immunol. 10, 2925. doi:10.3389/fimmu.2019. 02925

Martin, A. (2019). Bone and Heart Health in Chronic Kidney Disease. Curr. Opin. Nephrol. Hypertens. 28, 297-303. doi:10.1097/mnh.0000000000000512

Martin, A., David, V., and Quarles, L. D. (2012). Regulation and Function of the FGF23/Klotho Endocrine Pathways. Physiol. Rev. 92, 131-155. doi:10.1152/ physrev.00002.2011

Maycas, M., Ardura, J. A., de Castro, L. F., Bravo, B., Gortázar, A. R., and Esbrit, P. (2015). Role of the Parathyroid Hormone Type 1 Receptor (PTH1R) as a Mechanosensor in Osteocyte Survival. J. Bone Miner. Res. 30 (7), 1231-1244. doi:10.1002/jbmr.2439

McClung, M. R., Brown, J. P., Diez-Perez, A., Resch, H., Caminis, J., Meisner, P., et al. (2018). Effects of 24 Months of Treatment with Romosozumab Followed by 12 Months of Denosumab or Placebo in Postmenopausal Women with Low Bone Mineral Density: A Randomized, Double-Blind, Phase 2, Parallel Group Study. J. Bone Miner. Res. 33, 1397-1406. doi:10. $1002 / j b m r .3452$

McClung, M. R. (2017). Sclerostin Antibodies in Osteoporosis: Latest Evidence and Therapeutic Potential. Ther. Adv. Musculoskelet. 9, 263-270. doi:10.1177/ 1759720x17726744

McCreadie, B. R., and Hollister, S. J. (1997). Strain Concentrations Surrounding an Ellipsoid Model of Lacunae and Osteocytes. Computer Methods Biomech. Biomed. Eng. 1, 61-68. doi:10.1080/01495739708936695

McCutcheon, S., Majeska, R. J., Spray, D. C., Schaffler, M. B., and Vazquez, M. (2020). Apoptotic Osteocytes Induce RANKL Production in Bystanders via Purinergic Signaling and Activation of Pannexin Channels. J. Bone Miner. Res. 35, 966-977. doi:10.1002/jbmr.3954

McGarry, J. G., Klein-Nulend, J., and Prendergast, P. J. (2005). The Effect of Cytoskeletal Disruption on Pulsatile Fluid Flow-Induced Nitric Oxide and Prostaglandin E2 Release in Osteocytes and Osteoblasts. Biochem. Biophysical Res. Commun. 330, 341-348. doi:10.1016/j.bbrc.2005.02.175

McNamara, L. M., Majeska, R. J., Weinbaum, S., Friedrich, V., and Schaffler, M. B. (2009). Attachment of Osteocyte Cell Processes to the Bone Matrix. Anat. Rec. 292, 355-363. doi:10.1002/ar.20869

Merlotti, D., Gennari, L., Martini, G., Valleggi, F., De Paola, V., Avanzati, A., et al. (2007). Comparison of Different Intravenous Bisphosphonate Regimens for Paget's Disease of Bone. J. Bone Miner. Res. 22, 1510-1517. doi:10.1359/jbmr. 070704

Meshcheryakova, A., Mechtcheriakova, D., and Pietschmann, P. (2017). Sphingosine 1-phosphate Signaling in Bone Remodeling: Multifaceted Roles and Therapeutic Potential. Expert Opin. Ther. Targets 21, 725-737. doi:10.1080/ 14728222.2017 .1332180

Metz, L. N., Martin, R. B., and Turner, A. S. (2003). Histomorphometric Analysis of the Effects of Osteocyte Density on Osteonal Morphology and Remodeling. Bone 33, 753-759. doi:10.1016/s8756-3282(03)00245-x

Mirza, M. A. I., Larsson, A., Lind, L., and Larsson, T. E. (2009). Circulating Fibroblast Growth Factor-23 Is Associated with Vascular Dysfunction in the Community. Atherosclerosis 205, 385-390. doi:10.1016/j.atherosclerosis.2009. 01.001

Monteiro, D. A., Dole, N. S., Campos, J. L., Kaya, S., Schurman, C. A., Belair, C. D., et al. (2021). 'Fluid Shear Stress Generates a Unique Signaling Response by Activating Multiple TGF $\beta$ Family Type I Receptors in Osteocytes. Faseb j 35, e21263. doi:10.1096/fj.202001998r

Morello, R. (2018). Osteogenesis Imperfecta and Therapeutics. Matrix Biol. 71-72, 294-312. doi:10.1016/j.matbio.2018.03.010

Morrell, A. E., Brown, G. N., Robinson, S. T., Sattler, R. L., Baik, A. D., Zhen, G., et al. (2018). Mechanically Induced Ca2+ Oscillations in Osteocytes Release Extracellular Vesicles and Enhance Bone Formation. Bone Res. 6, 6. doi:10. 1038/s41413-018-0007-x

Morrell, A. E., Robinson, S. T., Ke, H. Z., Holdsworth, G., and Guo, X. E. (2021). Osteocyte Mechanosensing Following Short-Term and Long-Term Treatment with Sclerostin Antibody. Bone 149, 115967. doi:10.1016/j.bone.2021.115967

Murali, S. K., Andrukhova, O., Clinkenbeard, E. L., White, K. E., and Erben, R. G. (2016). Excessive Osteocytic Fgf23 Secretion Contributes to Pyrophosphate 
Accumulation and Mineralization Defect in Hyp Mice. Plos Biol. 14, e1002427. doi:10.1371/journal.pbio.1002427

Nakamura, H., Kenmotsu, S.-i., Sakai, H., and Ozawa, H. (1995). Localization of $\mathrm{CD} 44$, the Hyaluronate Receptor; on the Plasma Membrane of Osteocytes and Osteoclasts in Rat Tibiae. Cell Tissue Res. 280, 225-233. doi: $10.1007 / \mathrm{bf} 00307793$

Nakano, Y., Toyosawa, S., and Takano, Y. (2004). Eccentric Localization of Osteocytes Expressing Enzymatic Activities, Protein, and mRNA Signals for Type 5 Tartrate-Resistant Acid Phosphatase (TRAP). J. Histochem. Cytochem. 52, 1475-1482. doi:10.1369/jhc.4a6378.2004

Nguyen, J., Tang, S. Y., Nguyen, D., and Alliston, T. (2013). Load Regulates Bone Formation and Sclerostin Expression through a TGF $\beta$-dependent Mechanism. PLoS One 8, e53813. doi:10.1371/journal.pone.0053813

Nicolella, D. P., Moravits, D. E., Gale, A. M., Bonewald, L. F., Gale, A. M., Bonewald, L. F., et al. (2006). Osteocyte Lacunae Tissue Strain in Cortical Bone. J. Biomech. 39, 1735-1743. doi:10.1016/j.jbiomech.2005.04.032

Nicolella, D. P., Nicholls, A. E., Lankford, J., and Davy, D. T. (2001). Machine Vision Photogrammetry: a Technique for Measurement of Microstructural Strain in Cortical Bone. J. Biomech. 34, 135-139. doi:10.1016/s0021-9290(00)00163-9

Noonan, K. J., Stevens, J. W., Tammi, R., Tammi, M., Hernandez, J. A., and Midura, R. J. (1996). Spatial Distribution of CD44 and Hyaluronan in the Proximal Tibia of the Growing Rat. J. Orthop. Res. 14, 573-581. doi:10. 1002/jor.1100140411

Ominsky, M. S., Li, C., Li, X., Tan, H. L., Lee, E., Barrero, M., et al. (2011). Inhibition of Sclerostin by Monoclonal Antibody Enhances Bone Healing and Improves Bone Density and Strength of Nonfractured Bones. J. Bone Miner. Res. 26, 1012-1021. doi:10.1002/jbmr.307

Osterhoff, G., Morgan, E. F., Shefelbine, S. J., Karim, L., McNamara, L. M., and Augat, P. (2016). Bone Mechanical Properties and Changes with Osteoporosis. Injury 47 (Suppl. 2), S11-S20. doi:10.1016/s0020-1383(16)47003-8

Pajevic, P., Spatz, J., Garr, J., Adamson, C., and Misener, L. (2013). Osteocyte Biology and Space Flight. Cbiot 2, 179-183. doi:10.2174/ 22115501113029990017

Palumbo, C., Palazzini, S., and Marotti, G. (1990). Morphological Study of Intercellular Junctions during Osteocyte Differentiation. Bone 11, 401-406. doi:10.1016/8756-3282(90)90134-k

Pathak, J. L., Bravenboer, N., and Klein-Nulend, J. (2020). The Osteocyte as the New Discovery of Therapeutic Options in Rare Bone Diseases. Front. Endocrinol. 11, 405. doi:10.3389/fendo.2020.00405

Pathak, J. L., Bravenboer, N., Luyten, F. P., Verschueren, P., Lems, W. F., KleinNulend, J., et al. (2015). Mechanical Loading Reduces Inflammation-Induced Human Osteocyte-To-Osteoclast Communication. Calcif. Tissue Int. 97, 169-178. doi:10.1007/s00223-015-9999-Z

Pittenger, M. F., Mackay, A. M., Beck, S. C., Jaiswal, R. K., Douglas, R., Mosca, J. D., et al. (1999). Multilineage Potential of Adult Human Mesenchymal Stem Cells. Science 284, 143-147. doi:10.1126/science.284.5411.143

Plotkin, L. I., and Bellido, T. (2013). Beyond gap Junctions: Connexin43 and Bone Cell Signaling. Bone 52, 157-166. doi:10.1016/j.bone.2012.09.030

Plotkin, L. I., Mathov, I., Aguirre, J. I., Parfitt, A. M., Manolagas, S. C., and Bellido, T. (2005). Mechanical Stimulation Prevents Osteocyte Apoptosis: Requirement of Integrins, Src Kinases, and ERKs. Am. J. Physiology-Cell Physiol. 289, C633-C643. doi:10.1152/ajpcell.00278.2004

Plotkin, L. I., Weinstein, R. S., Parfitt, A. M., Roberson, P. K., Manolagas, S. C., and Bellido, T. (1999). Prevention of Osteocyte and Osteoblast Apoptosis by Bisphosphonates and Calcitonin. J. Clin. Invest. 104, 1363-1374. doi:10. $1172 /$ jci6800

Portal-Núñez, S., de la Fuente, M., Díez, A., and Esbrit, P. (2016). Oxidative Stress as a Possible Therapeutic Target for Osteoporosis Associated with Ageing. Rev. Osteoporos. Metab. Miner. 8, 138-146.

Prideaux, M., Findlay, D. M., and Atkins, G. J. (2016). Osteocytes: The Master Cells in Bone Remodelling. Curr. Opin. Pharmacol. 28, 24-30. doi:10.1016/j.coph. 2016.02.003

Qin, L., Liu, W., Cao, H., and Xiao, G. (2020). Molecular Mechanosensors in Osteocytes. Bone Res. 8, 23. doi:10.1038/s41413-020-0099-y

Qing, H., Ardeshirpour, L., Divieti Pajevic, P., Dusevich, V., Jähn, K., Kato, S., et al. (2012). Demonstration of Osteocytic Perilacunar/canalicular Remodeling in Mice during Lactation. J. Bone Miner. Res. 27, 1018-1029. doi:10.1002/jbmr. 1567
Qing, H., and Bonewald, L. F. (2009). Osteocyte Remodeling of the Perilacunar and Pericanalicular Matrix. Int. J. Oral Sci. 1, 59-65. doi:10.4248/ijos.09019

Qiu, S., Rao, D. S., Palnitkar, S., and Parfitt, A. M. (2002). Age and Distance from the Surface but Not Menopause Reduce Osteocyte Density in Human Cancellous Bone. Bone 31, 313-318. doi:10.1016/s87563282(02)00819-0

Ramesh, N., Moratti, S. C., and Dias, G. J. (2018). Hydroxyapatite-polymer Biocomposites for Bone Regeneration: A Review of Current Trends. J. Biomed. Mater. Res. 106, 2046-2057. doi:10.1002/ jbm.b.33950

Rath Bonivtch, A., Bonewald, L. F., and Nicolella, D. P. (2007). Tissue Strain Amplification at the Osteocyte Lacuna: A Microstructural Finite Element Analysis. J. Biomech. 40, 2199-2206. doi:10.1016/j.jbiomech. 2006.10.040

Recknor, C. P., Recker, R. R., Benson, C. T., Robins, D. A., Chiang, A. Y., Alam, J., et al. (2015). The Effect of Discontinuing Treatment with Blosozumab: Followup Results of a Phase 2 Randomized Clinical Trial in Postmenopausal Women with Low Bone Mineral Density. J. Bone Miner. Res. 30, 1717-1725. doi:10. 1002/jbmr.2489

Reilly, G. C., Haut, T. R., Yellowley, C. E., Donahue, H. J., and Jacobs, C. R. (2003). Fluid Flow Induced PGE2 Release by Bone Cells Is Reduced by Glycocalyx Degradation whereas Calcium Signals Are Not. Biorheology 40, 591-603.

Riquelme, M. A., Gu, S., Hua, R., and Jiang, J. X. (2021). Mechanotransduction via the Coordinated Actions of Integrins, PI3K Signaling and Connexin Hemichannels. Bone Res. 9, 8. doi:10.1038/s41413-020-00126-w

Riquelme, M. A., and Jiang, J. X. (2013). Elevated Intracellular Ca2+ Signals by Oxidative Stress Activate Connexin 43 Hemichannels in Osteocytes. Bone Res. 1, 355-361. doi:10.4248/br201304006

Rivadeneira, F., and Mäkitie, O. (2016). Osteoporosis and Bone Mass Disorders: From Gene Pathways to Treatments. Trends Endocrinol. Metab. 27, 262-281. doi:10.1016/j.tem.2016.03.006

Robling, A. G., and Turner, C. H. (2009). Mechanical Signaling for Bone Modeling and Remodeling. Crit. Rev. Eukar Gene Expr. 19, 319-338. doi:10.1615/ critreveukargeneexpr.v19.i4.50

Rochefort, G. Y. (2014). The Osteocyte as a Therapeutic Target in the Treatment of Osteoporosis. Ther. Adv. Musculoskelet. 6, 79-91. doi:10.1177/ $1759720 x 14523500$

Ru, J.-y., and Wang, Y.-f. (2020). Osteocyte Apoptosis: the Roles and Key Molecular Mechanisms in Resorption-Related Bone Diseases. Cell Death Dis. 11, 846. doi:10.1038/s41419-020-03059-8

Rubin, C. T., and Lanyon, L. E. (1984). Regulation of Bone Formation by Applied Dynamic Loads. J. Bone Jt. Surg. 66, 397-402. doi:10.2106/00004623198466030-00012

Rys, J. P., Monteiro, D. A., and Alliston, T. (2016). Mechanobiology of TGF $\beta$ Signaling in the Skeleton. Matrix Biol. 52-54, 413-425. doi:10.1016/j.matbio. 2016.02.002

Sandilos, J. K., Chiu, Y.-H., Chekeni, F. B., Armstrong, A. J., Walk, S. F., Ravichandran, K. S., et al. (2012). Pannexin 1, an ATP Release Channel, Is Activated by Caspase Cleavage of its Pore-Associated C-Terminal Autoinhibitory Region. J. Biol. Chem. 287, 11303-11311. doi:10.1074/jbc. m111.323378

Satir, P., Pedersen, L. B., and Christensen, S. T. (2010). The Primary Cilium at a Glance. J. Cel. Sci. 123, 499-503. doi:10.1242/jcs.050377

Sato, T., Verma, S., Andrade, C. D. C., Omeara, M., Campbell, N., Wang, J. S., et al. (2020). A FAK/HDAC5 Signaling axis Controls Osteocyte Mechanotransduction. Nat. Commun. 11, 3282. doi:10.1038/s41467-020-17099-3

Sauren, Y. M. H. F., Mieremet, R. H. P., Groot, C. G., and Scherft, J. P. (1992). An Electron Microscopic Study on the Presence of Proteoglycans in the Mineralized Matrix of Rat and Human Compact Lamellar Bone. Anat. Rec. 232, 36-44. doi:10.1002/ar.1092320105

Schaffler, M. B., Cheung, W.-Y., Majeska, R., and Kennedy, O. (2014). Osteocytes: Master Orchestrators of Bone. Calcif. Tissue Int. 94, 5-24. doi:10.1007/s00223013-9790-y

Schaffler, M. B., and Kennedy, O. D. (2012). Osteocyte Signaling in Bone. Curr. Osteoporos. Rep. 10, 118-125. doi:10.1007/s11914-012-0105-4

Schurman, C. A., Verbruggen, S. W., and Alliston, T. (2021). Disrupted Osteocyte Connectivity and Pericellular Fluid Flow in Bone with Aging and Defective 
TGF- $\beta$ Signaling. Proc. Natl. Acad. Sci. U S A. 118, 1. doi:10.1073/pnas. 2023999118

Scialla, J. J., Xie, H., Rahman, M., Anderson, A. H., Isakova, T., Ojo, A., et al. (2014). Fibroblast Growth Factor-23 and Cardiovascular Events in CKD. Jasn 25, 349-360. doi:10.1681/asn.2013050465

Sebastian, A., and Loots, G. G. (2018). Genetics of Sost/SOST in Sclerosteosis and Van Buchem Disease Animal Models. Metabolism 80, 38-47. doi:10.1016/j. metabol.2017.10.005

Seref-Ferlengez, Z., Urban-Maldonado, M., Sun, H. B., Schaffler, M. B., Suadicani, S. O., and Thi, M. M. (2019). Role of Pannexin 1 Channels in Load-Induced Skeletal Response. Ann. N. Y Acad. Sci. 1442, 79-90. doi:10. $1111 /$ nyas. 13914

Shah, F. A., Thomsen, P., and Palmquist, A. (2018). A Review of the Impact of Implant Biomaterials on Osteocytes. J. Dent. Res. 97, 977-986. doi:10.1177/ 0022034518778033

Shakeri, A., and Adanty, C. (2020). Romosozumab (Sclerostin Monoclonal Antibody) for the Treatment of Osteoporosis in Postmenopausal Women: A Review. jptcp 27, e25-e31. doi:10.15586/jptcp.v27i1.655

Shekaran, A., Shoemaker, J. T., Kavanaugh, T. E., Lin, A. S., LaPlaca, M. C., Fan, Y., et al. (2014). The Effect of Conditional Inactivation of Beta 1 Integrins Using Twist 2 Cre, Osterix Cre and Osteocalcin Cre Lines on Skeletal Phenotype. Bone 68, 131-141. doi:10.1016/j.bone.2014.08.008

Sims, N. A. (2016). Senescent Osteocytes: Do They Cause Damage and Can They Be Targeted to Preserve the Skeleton? J. Bone Miner. Res. 31, 1917-1919. doi:10. 1002/jbmr.2994

Spatz, J. M., Wein, M. N., Gooi, J. H., Qu, Y., Garr, J. L., Liu, S., et al. (2015). The Wnt Inhibitor Sclerostin Is Up-Regulated by Mechanical Unloading in Osteocytes In Vitro. J. Biol. Chem. 290, 16744-16758. doi:10.1074/jbc.m114. 628313

Sroga, G. E., and Vashishth, D. (2012). Effects of Bone Matrix Proteins on Fracture and Fragility in Osteoporosis. Curr. Osteoporos. Rep. 10, 141-150. doi:10.1007/ s11914-012-0103-6

Stavnichuk, M., Mikolajewicz, N., Corlett, T., Morris, M., and Komarova, S. V. (2020). A Systematic Review and Meta-Analysis of Bone Loss in Space Travelers. Npj Microgravity 6, 13. doi:10.1038/s41526-020-0103-2

Sterck, J. G. H., Klein-Nulend, J., Lips, P., and Burger, E. H. (1998). Response of normal and Osteoporotic Human Bone Cells to Mechanical Stress In Vitro. Am. J. Physiology-Endocrinology Metab. 274, E1113-E1120. doi:10.1152/ajpendo. 1998.274.6.e1113

Sudo, K., Kanno, M., Miharada, K., Ogawa, S., Hiroyama, T., Saijo, K., et al. (2007). Mesenchymal Progenitors Able to Differentiate into Osteogenic, Chondrogenic, And/or Adipogenic Cells In Vitro Are Present in Most Primary Fibroblast-Like Cell Populations. Stem Cells 25, 1610-1617. doi:10. 1634/stemcells.2006-0504

Suen, P. K., and Qin, L. (2016). Sclerostin, an Emerging Therapeutic Target for Treating Osteoporosis and Osteoporotic Fracture: A General Review. J. Orthopaedic Translation 4, 1-13. doi:10.1016/j.jot.2015. 08.004

Sun, N., Uda, Y., Azab, E., Kochen, A., Santos, R. N. C. E., Shi, C., et al. (2019). Effects of Histone Deacetylase Inhibitor Scriptaid and Parathyroid Hormone on Osteocyte Functions and Metabolism. J. Biol. Chem. 294, 9722-9733. doi:10. 1074/jbc.ra118.007312

Takata, S., Yonezu, H., Shibata, A., Enishi, T., Sato, N., Takahashi, M., et al. (2011). Mineral to Matrix Ratio Determines Biomaterial and Biomechanical Properties of Rat Femur -application of Fourier Transform Infrared Spectroscopy-. J. Med. Invest. 58, 197-202. doi:10.2152/jmi.58.197

Tanaka, M., Hashimoto, Y., Hasegawa, C., Deacon, S., and Eastell, R. (2017). Antiresorptive Effect of a Cathepsin K Inhibitor ONO-5334 and its Relationship to BMD Increase in a Phase II Trial for Postmenopausal Osteoporosis. BMC Musculoskelet. Disord. 18, 267. doi:10.1186/s12891-017$1625-\mathrm{y}$

Tavafoghi, M., and Cerruti, M. (2016). The Role of Amino Acids in Hydroxyapatite Mineralization. J. R. Soc. Interf. 13. doi:10.1098/rsif.2016.0462

Temiyasathit, S., and Jacobs, C. R. (2010). Osteocyte Primary Cilium and its Role in Bone Mechanotransduction. Ann. N. Y Acad. Sci. 1192, 422-428. doi:10.1111/j. 1749-6632.2009.05243.x

Temiyasathit, S., Tang, W. J., Leucht, P., Anderson, C. T., Monica, S. D., Castillo, A. B., et al. (2012). Mechanosensing by the Primary Cilium: Deletion of Kif3A
Reduces Bone Formation Due to Loading. PLoS One 7, e33368. doi:10.1371/ journal.pone.0033368

Termine, J. D., Kleinman, H. K., Whitson, S. W., Conn, K. M., McGarvey, M. L., and Martin, G. R. (1981). Osteonectin, a Bone-specific Protein Linking mineral to Collagen. Cell 26, 99-105. doi:10.1016/0092-8674(81)90037-4

Teti, A., and Zallone, A. (2009). Do osteocytes Contribute to Bone mineral Homeostasis? Osteocytic Osteolysis Revisited. Bone 44, 11-16. doi:10.1016/j. bone.2008.09.017

Thi, M. M., Suadicani, S. O., Schaffler, M. B., Weinbaum, S., and Spray, D. C. (2013). Mechanosensory Responses of Osteocytes to Physiological Forces Occur along Processes and Not Cell Body and Require V 3 Integrin. Proc. Natl. Acad. Sci. 110, 21012-21017. doi:10.1073/pnas.1321210110

Thompson, W. R., Majid, A. S., Czymmek, K. J., Ruff, A. L., García, J., Duncan, R. L., et al. (2011a). Association of the $\alpha 2 \delta 1$ Subunit with Cav3.2 Enhances Membrane Expression and Regulates Mechanically Induced ATP Release in MLO-Y4 Osteocytes. J. Bone Miner. Res. 26, 2125-2139. doi:10.1002/ jbmr.437

Thompson, W. R., Modla, S., Grindel, B. J., Czymmek, K. J., Kirn-Safran, C. B., Wang, L., et al. (2011b). Perlecan/Hspg2 Deficiency Alters the Pericellular Space of the Lacunocanalicular System Surrounding Osteocytic Processes in Cortical Bone. J. Bone Miner. Res. 26, 618-629. doi:10.1002/jbmr.236

Thompson, W. R., Scott, A., Loghmani, M. T., Ward, S. R., and Warden, S. J. (2016). Understanding Mechanobiology: Physical Therapists as a Force in Mechanotherapy and Musculoskeletal Regenerative Rehabilitation. Phys. Ther. 96, 560-569. doi:10.2522/ptj.20150224

Thompson, W. R., Yen, S. S., and Rubin, J. (2014). Vibration Therapy. Curr. Opin. Endocrinol. Diabetes Obes. 21, 447-453. doi:10.1097/med.0000000000000111

Thuy, A. V., Reimann, C.-M., Hemdan, N. Y. A., and Gräler, M. H. (2014). Sphingosine 1-Phosphate in Blood: Function, Metabolism, and Fate. Cell Physiol. Biochem. 34, 158-171. doi:10.1159/000362992

Tian, J., Ma, S., Xie, W.-Q., Zhang, Y.-M., Tao, L., Li, Y.-S., et al. (2021). Sphingosine 1-phosphate and Osteoporosis: Pathophysiology and Therapeutic Aspects-A Narrative Review. Ann. Palliat. Med. 10, 4799-4805. doi:10.21037/apm-20-1255

Tomkinson, A., Gevers, E. F., Wit, J. M., Reeve, J., and Noble, B. S. (1998). The Role of Estrogen in the Control of Rat Osteocyte Apoptosis. J. Bone Miner. Res. 13, 1243-1250. doi:10.1359/jbmr.1998.13.8.1243

Tong, X., Zhang, C., Wang, D., Song, R., Ma, Y., Cao, Y., et al. (2020). Suppression of AMP-Activated Protein Kinase Reverses Osteoprotegerin-Induced Inhibition of Osteoclast Differentiation by Reducing Autophagy. Cell Prolif. 53, e12714. doi:10.1111/cpr.12714

Tsourdi, E., Jähn, K., Rauner, M., Busse, B., and Bonewald, L. F. (2018). Physiological and Pathological Osteocytic Osteolysis. J. Musculoskelet. Neuronal Interact 18, 292-303.

Tu, X., Delgado-Calle, J., Condon, K. W., Maycas, M., Zhang, H., Carlesso, N., et al. (2015). Osteocytes Mediate the Anabolic Actions of Canonical Wnt $/ \beta$-Catenin Signaling in Bone. Proc. Natl. Acad. Sci. USA 112, E478-E486. doi:10.1073/ pnas. 1409857112

van Tol, A. F., Schemenz, V., Wagermaier, W., Roschger, A., Razi, H., Vitienes, I., et al. (2020). The Mechanoresponse of Bone Is Closely Related to the Osteocyte Lacunocanalicular Network Architecture. Proc. Natl. Acad. Sci. USA 117, 32251-32259. doi:10.1073/pnas.2011504117

Verborgt, O., Gibson, G. J., and Schaffler, M. B. (2000). Loss of Osteocyte Integrity in Association with Microdamage and Bone Remodeling after Fatigue In Vivo. J. Bone Miner. Res. 15, 60-67. doi:10.1359/jbmr.2000.15.1.60

Verbruggen, S. W., Mc Garrigle, M. J., Haugh, M. G., Voisin, M. C., and McNamara, L. M. (2015). Altered Mechanical Environment of Bone Cells in an Animal Model of Short- and Long-Term Osteoporosis. Biophysical J. 108, 1587-1598. doi:10.1016/j.bpj.2015.02.031

Verbruggen, S. W., Vaughan, T. J., and McNamara, L. M. (2012). Strain Amplification in Bone Mechanobiology: a Computational Investigation of the In Vivo Mechanics of Osteocytes. J. R. Soc. Interf. 9, 2735-2744. doi:10. 1098/rsif.2012.0286

Wang, B., Lai, X., Price, C., Thompson, W. R., Li, W., Quabili, T. R., et al. (2014). Perlecan-Containing Pericellular Matrix Regulates Solute Transport and Mechanosensing within the Osteocyte Lacunar-Canalicular System. J. Bone Miner. Res. 29, 878-891. doi:10.1002/jbmr.2105 
Wang, L., Dong, J., and Xian, C. J. (2015). Strain Amplification Analysis of an Osteocyte under Static and Cyclic Loading: a Finite Element Study. Biomed. Res. Int. 2015, 376474. doi:10.1155/2015/376474

Wang, T., Yu, X., and He, C. (2019). Pro-inflammatory Cytokines: Cellular and Molecular Drug Targets for Glucocorticoid-Induced-Osteoporosis via Osteocyte. Curr. Drug Targets 20, 1-15. doi:10.2174/ 1389450119666180405094046

Wang, Y., McNamara, L. M., Schaffler, M. B., and Weinbaum, S. (2007). A Model for the Role of Integrins in Flow Induced Mechanotransduction in Osteocytes. Proc. Natl. Acad. Sci. 104, 15941-15946. doi:10.1073/pnas. 0707246104

Wein, M. N., Spatz, J., Nishimori, S., Doench, J., Root, D., Babij, P., et al. (2015). HDAC5 Controls MEF2C-Driven Sclerostin Expression in Osteocytes. J. Bone Miner. Res. 30, 400-411. doi:10.1002/jbmr.2381

Weinbaum, S., Cowin, S. C., and Zeng, Y. (1994). A Model for the Excitation of Osteocytes by Mechanical Loading-Induced Bone Fluid Shear Stresses. J. Biomech. 27, 339-360. doi:10.1016/0021-9290(94)90010-8

Weinbaum, S., Tarbell, J. M., and Damiano, E. R. (2007). The Structure and Function of the Endothelial Glycocalyx Layer. Annu. Rev. Biomed. Eng. 9, 121-167. doi:10.1146/annurev.bioeng.9.060906.151959

Wenstrup, R. J., Willing, M. C., Starman, B. J., and Byers, P. H. (1990). Distinct Biochemical Phenotypes Predict Clinical Severity in Nonlethal Variants of Osteogenesis Imperfecta. Am. J. Hum. Genet. 46, 975-982.

Weske, S., Vaidya, M., von Wnuck Lipinski, K., Keul, P., Manthe, K., Burkhart, C., et al. (2019). Agonist-induced Activation of the S1P Receptor 2 Constitutes a Novel Osteoanabolic Therapy for the Treatment of Osteoporosis in Mice. Bone 125, 1-7. doi:10.1016/j.bone.2019.04.015

Whitaker, M., Guo, J., Kehoe, T., and Benson, G. (2012). Bisphosphonates for Osteoporosis - where Do We Go from Here? N. Engl. J. Med. 366, 2048-2051. doi:10.1056/nejmp1202619

Wittkowske, C., Reilly, G. C., Lacroix, D., and Perrault, C. M. (2016). In Vitro Bone Cell Models: Impact of Fluid Shear Stress on Bone Formation. Front. Bioeng. Biotechnol. 4, 87. doi:10.3389/fbioe.2016.00087

Wu, D., Ganatos, P., Spray, D. C., and Weinbaum, S. (2011). On the Electrophysiological Response of Bone Cells Using a Stokesian Fluid Stimulus Probe for Delivery of Quantifiable Localized picoNewton Level Forces. J. Biomech. 44, 1702-1708. doi:10.1016/j.jbiomech.2011.03.034

Wysolmerski, J. J. (2012). Parathyroid Hormone-Related Protein: An Update. J. Clin. Endocrinol. Metab. 97 (9), 2947-2956. doi:10.1210/jc.2012-2142

Xia, X., Batra, N., Shi, Q., Bonewald, L. F., Sprague, E., and Jiang, J. X. (2010). Prostaglandin Promotion of Osteocyte Gap Junction Function through Transcriptional Regulation of Connexin 43 by Glycogen Synthase Kinase 3/ $\beta$-Catenin Signaling. Mol. Cel. Biol. 30, 206-219. doi:10.1128/mcb.01844-08

Xiao, Z., Zhang, S., Mahlios, J., Zhou, G., Magenheimer, B. S., Guo, D., et al. (2006). Cilia-like Structures and Polycystin-1 in Osteoblasts/Osteocytes and Associated Abnormalities in Skeletogenesis and Runx2 Expression. J. Biol. Chem. 281, 30884-30895. doi:10.1074/jbc.m604772200

Xu, H., Zhang, J., Wu, J., Guan, Y., Weng, Y., and Shang, P. (2012). Oscillatory Fluid Flow Elicits Changes in Morphology, Cytoskeleton and IntegrinAssociated Molecules in MLO-Y4 Cells, but Not in MC3T3-E1 Cells. Biol. Res. 45, 163-169. doi:10.4067/s0716-97602012000200008

Yao, W., Dai, W., Jiang, L., Lay, E. Y.-A., Zhong, Z., Ritchie, R. O., et al. (2016). Sclerostin-antibody Treatment of Glucocorticoid-Induced Osteoporosis Maintained Bone Mass and Strength. Osteoporos. Int. 27, 283-294. doi:10. 1007/s00198-015-3308-6

Yavropoulou, M. P., and Yovos, J. G. (2016). The Molecular Basis of Bone Mechanotransduction. J. Musculoskelet. Neuronal Interact 16, 221-236.

Yokomoto-Umakoshi, M., Kanazawa, I., Takeno, A., Tanaka, K.-i., Notsu, M., and Sugimoto, T. (2016). Activation of AMP-Activated Protein Kinase Decreases Receptor Activator of NF-Kb Ligand Expression and Increases Sclerostin Expression by Inhibiting the Mevalonate Pathway in Osteocytic MLO-Y4 Cells. Biochem. Biophysical Res. Commun. 469, 791-796. doi:10.1016/j.bbrc. 2015.12.072
You, J., Yellowley, C. E., Donahue, H. J., Zhang, Y., Chen, Q., and Jacobs, C. R. (2000). Substrate Deformation Levels Associated with Routine Physical Activity Are Less Stimulatory to Bone Cells Relative to Loading-Induced Oscillatory Fluid Flow. J. Biomech. Eng. 122, 387-393. doi:10.1115/1.1287161

You, L.-D., Weinbaum, S., Cowin, S. C., and Schaffler, M. B. (2004). Ultrastructure of the Osteocyte Process and its Pericellular Matrix. Anat. Rec. 278A, 505-513. doi:10.1002/ar.a.20050

You, L., Cowin, S. C., Schaffler, M. B., and Weinbaum, S. (2001). A Model for Strain Amplification in the Actin Cytoskeleton of Osteocytes Due to Fluid Drag on Pericellular Matrix. J. Biomech. 34, 1375-1386. doi:10.1016/s0021-9290(01)00107-5

Young, M. F. (2003). Bone Matrix Proteins: Their Function, Regulation, and Relationship to Osteoporosis. Osteoporos. Int. 14 (Suppl. 3), S35-S42. doi:10. 1007/s00198-002-1342-7

Zambonin Zallone, A. Z., Teti, A., Nico, B., and Primavera, M. V. (1982). Osteoplastic Activity of Mature Osteocytes Evaluated by H-Proline Incorporation. Basic Appl. Histochem. 26, 65-67.

Zhang, C., Wei, W., Chi, M., Wan, Y., Li, X., Qi, M., et al. (2019b). FOXO1 Mediates Advanced Glycation End Products Induced Mouse Osteocyte-like MLO-Y4 Cell Apoptosis and Dysfunctions. J. Diabetes Res. 2019, 6757428. doi:10.1155/2019/6757428

Zhang, C., Bakker, A. D., Klein-Nulend, J., and Bravenboer, N. (2019a). Studies on Osteocytes in Their 3D Native Matrix versus 2D In Vitro Models. Curr. Osteoporos. Rep. 17, 207-216. doi:10.1007/s11914-019-00521-1

Zhang, C., Xu, S., Zhang, S., Liu, M., Du, H., Sun, R., et al. (2019c). Ageing Characteristics of Bone Indicated by Transcriptomic and Exosomal Proteomic Analysis of Cortical Bone Cells. J. Orthop. Surg. Res. 14, 129. doi:10.1186/ s13018-019-1163-4

Zhang, J.-N., Zhao, Y., Liu, C., Han, E. S., Yu, X., Lidington, D., et al. (2015). The Role of the Sphingosine-1-Phosphate Signaling Pathway in Osteocyte Mechanotransduction. Bone 79, 71-78. doi:10.1016/j.bone. 2015.05.017

Zhang, L., Dong, Y., Wang, Y., Hu, W., Dong, S., and Chen, Y. (2020). Sphingosine-1-phosphate (S1P) Receptors: Promising Drug Targets for Treating Bone-related Diseases. J. Cel. Mol. Med. 24, 4389-4401. doi:10. $1111 /$ jcmm. 15155

Zhou, C., Wang, Q., Zhang, D., Cai, L., Du, W., and Xie, J. (2019). Compliant Substratum Modulates Vinculin Expression in Focal Adhesion Plaques in Skeletal Cells. Int. J. Oral Sci. 11, 18. doi:10.1038/s41368019-0052-3

Zimmerman, D., Jin, F., Leboy, P., Hardy, S., and Damsky, C. (2000). Impaired Bone Formation in Transgenic Mice Resulting from Altered Integrin Function in Osteoblasts. Developmental Biol. 220, 2-15. doi:10.1006/ dbio.2000.9633

Zimmerman, S. M., Dimori, M., Heard-Lipsmeyer, M. E., and Morello, R. (2019). The Osteocyte Transcriptome Is Extensively Dysregulated in Mouse Models of Osteogenesis Imperfecta. JBMR Plus 3, e10171. doi:10.1002/jbm4.10171

Conflict of Interest: The authors declare that the research was conducted in the absence of any commercial or financial relationships that could be construed as a potential conflict of interest.

Publisher's Note: All claims expressed in this article are solely those of the authors and do not necessarily represent those of their affiliated organizations, or those of the publisher, the editors and the reviewers. Any product that may be evaluated in this article, or claim that may be made by its manufacturer, is not guaranteed or endorsed by the publisher.

Copyright (c) 2022 Choi, Kijas, Lauko and Rowan. This is an open-access article distributed under the terms of the Creative Commons Attribution License (CC BY). The use, distribution or reproduction in other forums is permitted, provided the original author(s) and the copyright owner(s) are credited and that the original publication in this journal is cited, in accordance with accepted academic practice. No use, distribution or reproduction is permitted which does not comply with these terms. 